\title{
Winter climate changes over East Asian region under RCP scenarios using East Asian winter monsoon indices
}

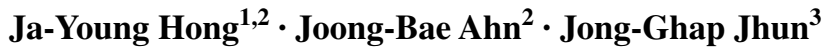

Received: 28 July 2015 / Accepted: 19 March 2016 / Published online: 28 March 2016

(C) The Author(s) 2016. This article is published with open access at Springerlink.com

\begin{abstract}
The changes in the winter climatology and variability of the East Asian winter monsoon (EAWM) for the late 21st century (2070-2099) under the Representative Concentration Pathway (RCP) 4.5 and 8.5 scenarios are projected in terms of EAWM indices (EAWMIs). Firstly, the capability of the climate models participating in the Coupled Model Intercomparison Project phase 5 (CMIP5) in simulating the boreal winter climatology and the interannual variability of the EAWM for the late 20th century (1971-2000) is examined. Nine of twenty-three climate models are selected based on the pattern correlations with observation and a multi-model ensemble is applied to the nine model data. Three of twelve EAWMIs that show the most significant temporal correlations between the observation and CMIP5 surface air temperatures are utilized. The ensemble CMIP5 is capable of reproducing the overall features of the EAWM in spite of some biases in the region. The negative correlations between the EAWMIs and boreal winter temperature are well reproduced and 3-5 years of the major interannual variation observed in this region are also well simulated according to power spectral analyses of the simulated indices. The fields regressed onto the indices
\end{abstract}

Joong-Bae Ahn

jbahn@pusan.ac.kr

1 Division of Polar Climate Change, Korea Polar Research Institute, 26, Songdomirae-ro, Yeonsu-gu, Incheon 21990, South Korea

2 Division of Earth Environmental System, Department of Atmospheric sciences, Pusan National University, 2, Busandaehak-ro 63beon-gil, Geumjeong-gu, Busan 46241, South Korea

3 School of Earth and Environmental Sciences, Seoul National University, 1, Gwanak-ro, Gwanak-gu, Seoul 08826, South Korea that resemble the composite strong winter monsoon pattern are simulated more or less weakly in CMIP5 compared to the observation. However, the regressed fields of sea level pressure, surface air temperature, 500-hPa geopotential height, and 300-hPa zonal wind are well established with pattern correlations above 0.83 between CMIP5 and observation data. The differences between RCPs and Historical indicate strong warming, which increases with latitude, ranging from 1 to $5{ }^{\circ} \mathrm{C}$ under RCP4.5 and from 3 to $7{ }^{\circ} \mathrm{C}$ under RCP8.5 in the East Asian region. The anomalous southerly winds generally become stronger, implying weaker EAWMs in both scenarios. These features are also identified with fields regressed onto the indices in RCPs. The future projections reveal that the interannual variability of the indices will be maintained with an intensity similar to that of the present. The correlation between monsoon indices and Arctic Oscillation increases over time. On the other hand, the correlation between monsoon indices and North Atlantic Oscillation decreases.

Keywords Climate change $\cdot$ RCP scenarios $\cdot$ East Asian winter monsoon $\cdot$ CMIP5 $\cdot$ Monsoon index

\section{Introduction}

The East Asian winter monsoon (EAWM), which is related to the Siberian High (SH), the Aleutian Low (AL), lowlevel northerly winds, and the surface air temperature over eastern China, Korea, and Japan, is the major climate component in East Asia (EA) during the boreal winter (Lau and Li 1984; Chang et al. 2006; Wang et al. 2013). The interannual variability of EAWM is known to be associated with the El Nino-Southern Oscillation (e.g., Lau and Chang 1987; Zhang et al. 1996; Huang et al. 2004; Li et al. 2007; 
Wang et al. 2008), the Arctic Oscillation (AO) (e.g., Gong et al. 2001; Wu and Wang 2002), Tibetan Plateau effect (e.g., Zhisheng et al. 2001; Yanai and Wu 2006), Eurasian snow cover (e.g., Watanabe and Nitta 1999; Wu and Wang 2002; Jhun and Lee 2004), and autumn Arctic sea ice (e.g., Liu et al. 2012). Therefore, the understanding, predictability and future projection of the EAWM variability are crucial in many respects, particularly for the various industrial activities and human life in the region.

The coupled general circulation model (CGCM) is an ultimate tool to describe the possible future change as well as the mechanism of EAWM (Kharin et al. 2007; Gong et al. 2014). However, limited studies have been performed to enhance our understanding of the EAWM under future climate change scenarios (Wei and Bao 2012; Gong et al. 2014) because of its complicated thermodynamics (Wang et al. 2001). Using a CGCM, Hu et al. (2000) showed that the intensity of the EAWM weakens but the variances of the EAWM on the interannual and interdecadal scales are not much affected by global warming. Bueh (2003) simulated the changes of the EAWM using a CGCM under A2 and B2 scenarios and claimed that the global warming reduces the EAWM circulation. Hori and Ueda (2006) evaluated nine CGCMs and found that the weakening of the tropical local Hadley circulation is likely to weaken the EA Jet and the resultant EAWM under A1B scenario. These studies focused on the changes of the EAWM under global warming emissions scenarios (IPCC 2000).

Compared with CMIP phase 3 (CMIP3), CMIP5 includes more comprehensive models which have higherspatial-resolution and more sophisticated treatment of the physical processes involved in the earth system, including the carbon cycle, ocean biogeochemistry, and dynamic vegetation processes (Taylor et al. 2012). The new future forcing scenarios (Taylor et al. 2012) are also applied to CMIP5. Gong et al. (2014) assessed the interannual variability of the EAWM-related circulations of present-day simulations using 18 CMIP5 models and found that most of the models can capture and reproduce variabilities and circulations. Using CMIP5 model data, Wei and Bao (2012) argued that the EAWM became stronger and that interannual variability of temperature increased (decreased) around lower (higher) latitudes in future projections. Jiang and Tian (2013) evaluated the changes in the EAWM under the impact of global warming in 23 CMIP3 and 19 CMIP5 models and obtained similar results to Wei and Bao (2012). Gong et al. (2014) analyzed the climatology and interannual variations of the EAWM under the current climate, Wei and Bao (2012) used a single CGCM, and Jiang and Tian (2013) focused on changes of the EAWM in terms of only time series and mean fields.

A representative and comprehensive index is often used efficiently in the EAWM studies (Wang and Chen 2014).
Many researchers have tried to define the EAWM indices (EAWMIs) in order to quantify the strength of the EAWM. According to Wang and Chen (2010), EAWMIs can be classified into four types: (1) east-west pressure gradient indices (e.g., Wu and Wang 2002; Chan and Li 2004; Wang et al. 2009b; Wang and Chen 2014), (2) low-level meridional wind indices (e.g., Ji et al. 1997; Lu and Chan 1999; Yang et al. 2002), (3) upper-level zonal wind shear indices (e.g., Jhun and Lee 2004; Zhu 2008; Li and Yang 2010), and (4) EA trough indices (e.g., Wang et al. 2009a; Wang and He 2012). The EAWM-related circulation and air temperature anomalies are well delineated by these indices (Ji et al. 1997; Jhun and Lee 2004; Wang and Chen 2010, 2014).

Therefore, the present study goal is to examine the performance of reproducibility of the EA winter atmospheric circulations using the CMIP5 dataset and its future change under the Representative Concentration Pathway (RCP) 4.5 and 8.5 in terms of EAWMIs. Section 2 describes reanalysis datasets and presents a brief description of the models and analysis method. The CGCM performance for the simulation of the present-day climate is included in Sect. 3, and the future changes in the EAWM are presented in Sect. 4. Section 5 gives the summary and discussion.

\section{Model and data}

The European Centre for Medium-Range Weather Forecasts Reanalysis 40 (ERA40) dataset (Uppala et al. 2005) are used for air temperature at 2-m height (T2m), sea level pressure (SLP), 850-hPa zonal/meridional winds (UV850), $500-\mathrm{hPa}$ geopotential height (Z500), and $300-\mathrm{hPa}$ zonal wind (U300). The horizontal resolution of the dataset is $2.5^{\circ}$ in both longitude and latitude. The sea surface temperature (SST) data used here are from the Hadley Centre Sea Ice and SST (HadISST) dataset (Rayner et al. 2003), which has a $1^{\circ} \times 1^{\circ}$ horizontal resolution. The ERA40 and HadISST datasets are referred to as observations, hereafter.

The T2m and SLP of 23 models that provide both Historical (present-day simulation) and RCP4.5/8.5 (future projections) datasets are evaluated in terms of the spatial correlation coefficient and the Empirical Orthogonal Function (EOF) analyses in association with EAWM. Among these models, we selected nine models of which the spatial correlation coefficient for the leading mode of EOF over EA $\left(20^{\circ} \mathrm{N}-60^{\circ} \mathrm{N}, 100^{\circ} \mathrm{E}-150^{\circ} \mathrm{E}\right)$ between each model output for Historical and observation is larger than 0.8 for both T2m and SLP. Table 1 summarizes the model configurations used in our study. The first ensemble member from each model under Historical has been assessed. The analysis period for Historical and RCP4.5/8.5 is 30 years from $1971 / 72$ to $2000 / 01$ and from $2070 / 71$ to $2099 / 100$, 
Table 1 The configuration of the CMIP5 models used in this study

\begin{tabular}{|c|c|c|c|}
\hline Modelling group & Model & $\begin{array}{l}\text { Atmosphere resolution } \\
\text { (horizontal, vertical) }\end{array}$ & $\begin{array}{l}\text { Ocean resolution } \\
\text { (horizontal, vertical) }\end{array}$ \\
\hline $\begin{array}{l}\text { Canadian Centre for Climate Modelling and Analy- } \\
\text { sis }\end{array}$ & CanESM2 & T63, L35 & $256 \times 192, \mathrm{~L} 40$ \\
\hline \multirow{3}{*}{$\begin{array}{l}\text { National Oceanic and Atmospheric Administration } \\
\text { Geophysical Fluid Dynamics Laboratory }\end{array}$} & GFDL-CM3 & C48, L48 & $360 \times 200$, L50 \\
\hline & GFDL-ESM2G & M45, L24 & $360 \times 210, \mathrm{~L} 63$ \\
\hline & GFDL-ESM2 M & M45, L24 & $360 \times 200, \mathrm{~L} 50$ \\
\hline \multirow{2}{*}{$\begin{array}{l}\text { National Aeronautics and Space Administration } \\
\text { Goddard Institute for Space Studies }\end{array}$} & GISS-E2-H & $144 \times 90, \mathrm{~L} 40$ & $144 \times 90, \mathrm{~L} 26$ \\
\hline & GISS-E2-R & $144 \times 90, \mathrm{~L} 40$ & $144 \times 90, \mathrm{~L} 32$ \\
\hline Met Office Hadley Centre & HadGEM2-CC & N96, L60 & $360 \times 216, \mathrm{~L} 40$ \\
\hline $\begin{array}{l}\text { Atmosphere and Ocean Research Institute, National } \\
\text { Institute for Environmental Studies, and Japan } \\
\text { Agency for Marine-Earth Science and Technology }\end{array}$ & MIROC5 & $\mathrm{T} 85, \mathrm{~L} 40$ & $256 \times 224$, L50 \\
\hline Max Planck Institute for Meteorology & MPI-ESM-MR & T63, L95 & TP04, L40 \\
\hline
\end{tabular}

respectively. The seasonal mean is calculated by averaging the monthly data of December, January, and February (DJF), corresponding to 30 boreal winters of 1971/722000/01 and 2070/71-2099/100. Hereafter, the DJF (winter) of 1972 denotes December of 1971, and January and February of 1972 as an example.

The multi-model ensemble (MME) is an effective method to analyze the capability of models (Sperber et al. 2012) and the MME performs better than individual models in simulation and prediction, particularly over EA (Jiang et al. 2005; Chen and Sun 2013). Thus, the model results are presented as an MME and the model data are regridded to the observation grids. The standardized anomalies are also used in this study considering the characteristics of MME that reduce the variation of variable compared to observation. The significance of the model results is estimated based on Student's $t$ test.

The temperature is considered the most important meteorological variable representing EAWM (Wang and Chen 2010). To choose suitable EAWMIs, the correlation coefficients between EAWMIs and winter T2m over EA (EA-T2m index), which is defined as the winter T2m anomaly averaged over the domain of $30^{\circ} \mathrm{N}-50^{\circ} \mathrm{N}$ and $110^{\circ} \mathrm{E}-140^{\circ} \mathrm{E}$, are calculated (Table 2). In observation, the EAWMIs generally have close relationships with EA$\mathrm{T} 2 \mathrm{~m}$. However, correlation coefficients between low-level meridional wind indices and EA-T2m are not significant in Historical. Hence, the EAWMIs that have the highest correlation coefficient with EA-T2m in each type excluding the meridional wind type are chosen in this study. In each type, indices of Wang and Chen (2014) (hereafter, $\mathrm{I}_{\mathrm{WC}}$ ), Jhun and Lee (2004) (hereafter, $\mathrm{I}_{\mathrm{JL}}$ ), and Wang and He (2012) (hereafter, $\mathrm{I}_{\mathrm{WH}}$ ) have robust correlations with EA-T2m in both observation and Historical. Therefore, the three EAWMIs defined as below are selected as the indices for this study.
Table 2 Temporal correlation coefficients between the EAWMIs and EA-T2 $\mathrm{m}$ in observation and Historical

\begin{tabular}{|c|c|c|c|c|}
\hline \multirow[t]{2}{*}{ Type } & \multirow[t]{2}{*}{ Variable } & \multirow[t]{2}{*}{ References } & \multicolumn{2}{|c|}{ Correlation coefficient } \\
\hline & & & Observation & Historical \\
\hline \multirow[t]{4}{*}{$\begin{array}{l}\text { East-west gradi- } \\
\text { ent }\end{array}$} & SLP & $\begin{array}{l}\text { Wu and Wang } \\
(2002)\end{array}$ & $-0.69 * *$ & $-0.57 * *$ \\
\hline & SLP & $\begin{array}{l}\text { Chan and Li } \\
\text { (2004) }\end{array}$ & $-0.59 * *$ & $-0.60 * *$ \\
\hline & $\mathrm{SLP}^{\dagger}$ & $\begin{array}{l}\text { Wang et al. } \\
(2009 b)\end{array}$ & $-0.59^{* *}$ & $-0.46^{*}$ \\
\hline & $\mathrm{SLP}^{\dagger}$ & $\begin{array}{l}\text { Wang and Chen } \\
\text { (2014) }\end{array}$ & $-0.74 * *$ & $-0.76^{* *}$ \\
\hline \multirow[t]{3}{*}{ Meridional wind } & V1000 & Ji et al. (1997) & $-0.44^{*}$ & -0.07 \\
\hline & V1000 & $\begin{array}{l}\text { Lu and Chan } \\
\text { (1999) }\end{array}$ & -0.36 & -0.17 \\
\hline & V850 & $\begin{array}{l}\text { Yang et al. } \\
\text { (2002) }\end{array}$ & $-0.39 *$ & -0.12 \\
\hline \multirow[t]{3}{*}{ Zonal wind shear } & $\mathrm{U} 300$ & $\begin{array}{l}\text { Jhun and Lee } \\
\text { (2004) }\end{array}$ & $-0.69 * *$ & $-0.54 * *$ \\
\hline & U500 & Zhu (2008) & $-0.66 * *$ & $-0.57 * *$ \\
\hline & U200 & $\begin{array}{l}\text { Li and Yang } \\
\text { (2010) }\end{array}$ & $-0.66^{* *}$ & -0.29 \\
\hline \multirow[t]{2}{*}{ EA trough } & $\mathrm{Z} 500$ & $\begin{array}{l}\text { Wang et al. } \\
\text { (2009a) }\end{array}$ & $-0.47 * *$ & $-0.81 * *$ \\
\hline & $\mathrm{Z} 500$ & $\begin{array}{l}\text { Wang and } \mathrm{He} \\
\text { (2012) }\end{array}$ & $-0.80^{* *}$ & $-0.75^{* *}$ \\
\hline
\end{tabular}

One and two asterisks denote the statistical significance at the 5 and $1 \%$ significance levels, respectively. SLP $^{\dagger}$ represents normalized anomalies of sea level pressure

$$
\begin{aligned}
& \mathrm{I}_{\mathrm{WC}}=\left(2 \times \mathrm{SLP}_{1}{ }^{*}-\mathrm{SLP}_{2}{ }^{*}-\mathrm{SLP}_{3} *\right) / 2, \\
& \mathrm{I}_{\mathrm{JL}}=\mathrm{U} 300\left(27.5^{\circ} \mathrm{N}-37.5^{\circ} \mathrm{N}, 110^{\circ} \mathrm{E}-170^{\circ} \mathrm{E}\right)-\mathrm{U} 300 \\
& \left(50^{\circ} \mathrm{N}-60^{\circ} \mathrm{N}, 80^{\circ} \mathrm{E}-140^{\circ} \mathrm{E}\right), \\
& \mathrm{I}_{\mathrm{WH}}=\mathrm{Z} 500\left(25^{\circ} \mathrm{N}-45^{\circ} \mathrm{N}, 110^{\circ} \mathrm{E}-145^{\circ} \mathrm{E}\right),
\end{aligned}
$$


where $\mathrm{SLP}_{1} *, \mathrm{SLP}_{2} *$, and $\mathrm{SLP}_{3} *$ indicate the normalized area-averaged SLP over $\left(40^{\circ} \mathrm{N}-60^{\circ} \mathrm{N}, 70^{\circ} \mathrm{E}-120^{\circ} \mathrm{E}\right)$, $\left(30^{\circ} \mathrm{N}-50^{\circ} \mathrm{N}, \quad 140^{\circ} \mathrm{E}-170^{\circ} \mathrm{W}\right), \quad$ and $\left(20^{\circ} \mathrm{S}-10^{\circ} \mathrm{N}\right.$, $110^{\circ} \mathrm{E}-160^{\circ} \mathrm{E}$ ), respectively (Wang and Chen 2014).

In order to investigate the changes in teleconnection, five other climatic indices are also used in this study: (1) the North Pacific (NP) index, which is defined as the winter SLP anomaly averaged over the domain of $30^{\circ} \mathrm{N}-65^{\circ} \mathrm{N}$ and $160^{\circ} \mathrm{E}-140^{\circ} \mathrm{W}$ (Trenberth and Hurrell 1994), (2) the Niño-3.4 index, which is defined as the SST anomaly averaged over the region of $5^{\circ} \mathrm{S}-5^{\circ} \mathrm{N}$ and $170^{\circ} \mathrm{E}-120^{\circ} \mathrm{W}$, (3) the North Atlantic Oscillation (NAO) index, which is defined as half of the difference in the SLP anomaly between $\left(40^{\circ} \mathrm{N}, 10^{\circ} \mathrm{W}\right)$ and $\left(65^{\circ} \mathrm{N}, 20^{\circ} \mathrm{W}\right)$ (Hurrell 1995), (4) the $\mathrm{SH}$ index, which is defined as the SLP anomaly averaged over the domain of $40^{\circ} \mathrm{N}-60^{\circ} \mathrm{N}$ and $80^{\circ} \mathrm{E}-120^{\circ} \mathrm{E}$, and (5) the $\mathrm{AO}$ index, which is defined as the principal component of the first EOF mode for the winter SLP anomaly poleward of $20^{\circ} \mathrm{N}$ (Thompson and Wallace 1998).

\section{Evaluation of historical performance}

The DJF mean bias of Historical and climatology of observation over EA are shown in Fig. 1. The Historical results indicate lower (higher) SLP over the $\mathrm{SH}$ region and to the southwest of AL (over the Tibetan Plateau and to the north of AL). The warm (cold) bias at the surface is significant over the $\mathrm{SH}$ region extending to the zonal direction (over the Tibetan Plateau and the northwestern Pacific). The magnitude of the T2m bias is larger over land than over ocean. For the $850-\mathrm{hPa}$ wind, the anomalous anticyclonic wind biases are located in the $\mathrm{SH}$ region and northern China in Historical. And the anomalous cyclonic circulation centered at around Primorsky Kray (Maritime Provinces of Siberia) is pronounced, resulting in weaker wind over the region of western branch of AL compared to the observation owing to the underestimated SLP gradient between $\mathrm{SH}$ and AL. In the middle troposphere, the negative bias in the $\mathrm{Z} 500$ is pronounced in the domain, particularly over the $\mathrm{SH}$ region and EA trough region. As a result, the trough is deep in Historical over the EA trough region, indicating a strong north-south gradient of Z500 compared to the observation. The stronger Z500 trough may be associated with model bias in simulating the global-scale geopotential height lower in the mid and high latitudes compared to the observation, resulting in a stronger polar vortex due to increased meridional geopotential height gradient (Wei et al. 2014). The center of the jet stream is shifted southward and the zonal wind speed weakens to the north of the observed jet location at $300 \mathrm{hPa}$ in Historical. These results are similar to those of Gong et al. (2014).
The time series of the normalized EAWMIs and the EA$\mathrm{T} 2 \mathrm{~m}$ index for observation and Historical during the boreal winter are illustrated in Fig. 2. They generally exhibit the decadal weakening of EAWM after the mid-1980s in observation (Jhun and Lee 2004; Wang and He 2012; Lee et al. 2013; Wang and Chen 2014). Three to six and four to eight strong and weak monsoon years, respectively, exceed positive and negative of one standard deviation (SD) of each index. The numbers of cold and warm years that exceed positive and negative of one SD of each index, respectively, are equal to six in observation. Among the three EAWMIs, strong positive $\mathrm{I}_{\mathrm{WH}}$ and $\mathrm{I}_{\mathrm{JL}}$ generally match with the strong negative EA-T2m index. However, not every strong positive EA-T2m index corresponds robustly to the negative EAWMIs, whereas the weak monsoons seem to closely match with the warm EA-T2m. In Historical, which shows a decadal change roughly similar with observation, the numbers of strong (weak) monsoon years are four to seven (six to ten), as in observation, except for those of the weak monsoon years of $\mathrm{I}_{\mathrm{WH}}$. Historical also reasonably simulates the mutual relation between the positive (negative) EAWMIs and cold (warm) EA-T2m.

Figure 3 displays the power spectra of each index for the observed and simulated EAWMIs. The primary (secondary) peaks of $\mathrm{I}_{\mathrm{WC}}, \mathrm{I}_{\mathrm{JL}}$, and $\mathrm{I}_{\mathrm{WH}}$ for observation are 3.7 (5.0) year, 3.7 (5.0) year, and 3.3 (5.0) year, respectively. Such interannual variabilities of the EAWMIs (Jhun and Lee 2004; Gao 2007) are also apparent in Historical; the major periods of $\mathrm{I}_{\mathrm{WC}}$ and $\mathrm{I}_{\mathrm{JL}}$ are both 3.3 year, and $\mathrm{I}_{\mathrm{WH}}$ exhibits a major period of 5.0 year. This implies that Historical actually captures the interannual variabilities found in observation in terms of the power spectra of the three indices.

The winter atmospheric fields regressed onto the EAWMIs in observation and Historical are exhibited in Figs. 4 and 5, respectively. These regressed fields are very similar to their composite patterns for strong monsoons (data not shown). In observation (Fig. 4), the strong EAWM is characterized by the developed $\mathrm{SH}$ and the deepened AL, which are consistent with previous results (e.g., Jhun and Lee 2004; Chen et al. 2005; Wang et al. 2009; Gao et al. 2014). Also, it is associated with colder $\mathrm{T} 2 \mathrm{~m}$, strengthened northerly wind at $850 \mathrm{hPa}$, reinforced EA trough at $500 \mathrm{hPa}$, and increased jet stream at $300 \mathrm{hPa}$ over EA. The patterns of regressed fields by the three EAWMIs are similar with each other. In more detail, the regressed SLP over the SH region, Z500 over the EA trough region, and U300 over the EA jet region are robust in $\mathrm{I}_{\mathrm{WC}}, \mathrm{I}_{\mathrm{WH}}$, and $\mathrm{I}_{\mathrm{JL}}$, respectively, compared to the other two EAWMIs. The reason is because the indices of $\mathrm{I}_{\mathrm{WC}}, \mathrm{I}_{\mathrm{WH}}$, and $\mathrm{I}_{\mathrm{JL}}$ are defined by SLP, Z500, and $\mathrm{U} 300$, respectively, as illustrated in Sect. 2. In T2m especially, the fields regressed onto $\mathrm{I}_{\mathrm{WH}}$ are larger than those onto the other EAWMIs over the EA region. 

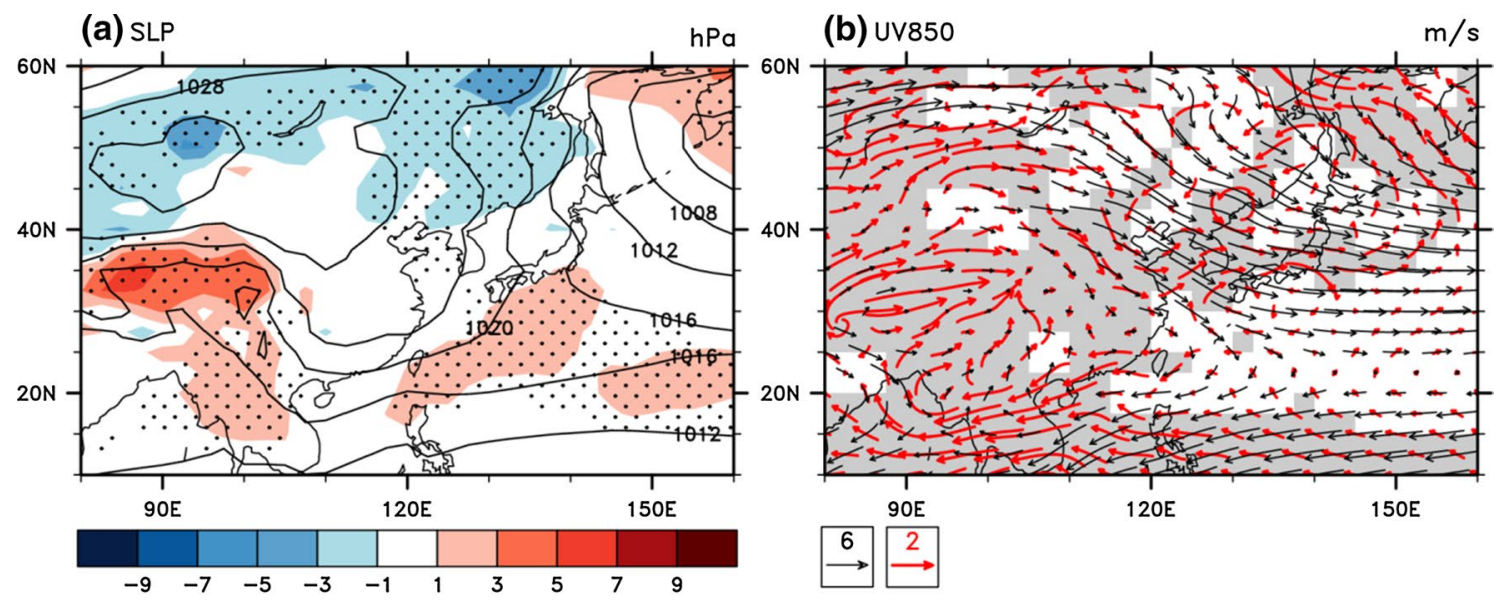

(c) $\mathrm{T} 2 \mathrm{~m}$

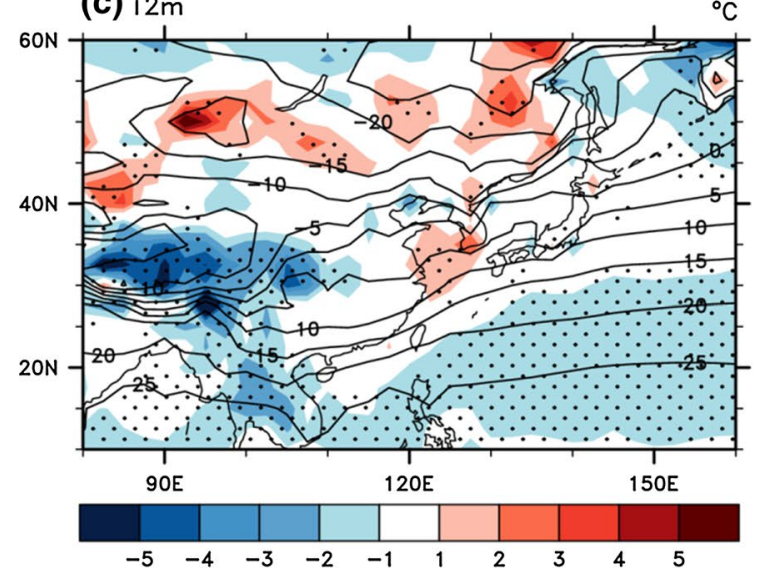

(d) 7500

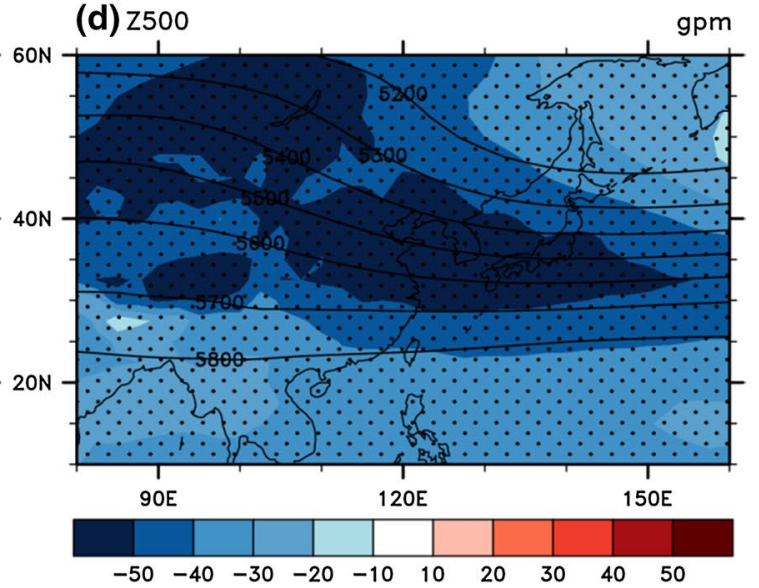

(e) $\cup 300$

$\mathrm{m} / \mathrm{s}$

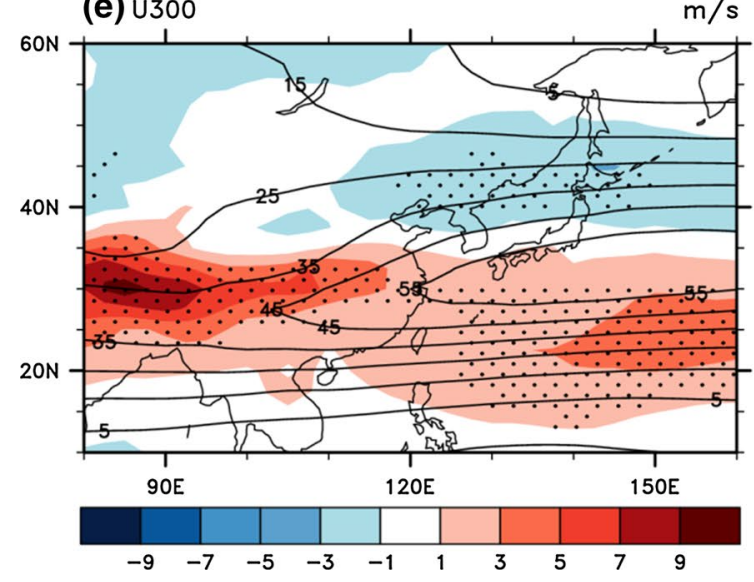

Fig. 1 The differences of DJF mean climatological fields (1971/722000/01) of a sea level pressure, b $850-\mathrm{hPa}$ winds, c temperature at 2-m height, d 500-hPa geopotential height, and e 300-hPa zonal wind speed between Historical and observation (bluelred shadings and red

The regressed patterns of SLP onto the indices are similar to the observation with pattern correlations of above 0.85 (Fig. 5), although the fields of SLP regressed onto $\mathrm{I}_{\mathrm{WH}}$ $\left(\mathrm{I}_{\mathrm{WC}}\right.$ and $\mathrm{I}_{\mathrm{JL}}$ ) are somewhat stronger (weaker) over NP in Historical than in observation. The regressed fields of SLP arrows). Contours and black arrows are climatology of observation. The grid points exceeding the $95 \%$ confidence level of $t$ test are dotted or shaded in gray

in Historical over SH are weaker than those in observation, since SH in Historical is simulated somewhat weaker than in observation (Fig. 1). The cold anomaly centers of T2m and the flow patterns of wind anomalies resemble observation, although the simulated cold $\mathrm{T} 2 \mathrm{~m}$ anomalies over 
Fig. 2 Time series of the normalized $\mathrm{I}_{\mathrm{WC}}$ (red), $\mathrm{I}_{\mathrm{JL}}$ (green), $\mathrm{I}_{\mathrm{WH}}($ blue $)$ and EA-T2m index (gray bars) for a observation and $\mathbf{b}$ Historical for the period 1971/72-2000/01

\section{(a) OBS}

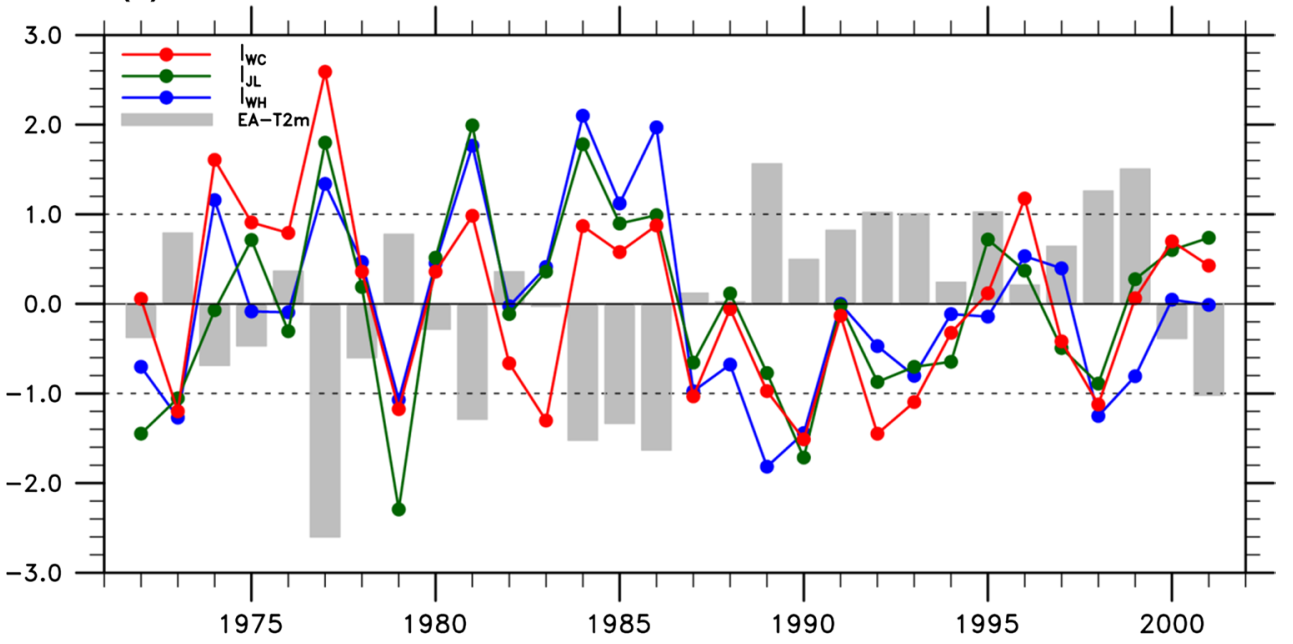

(b) Historical

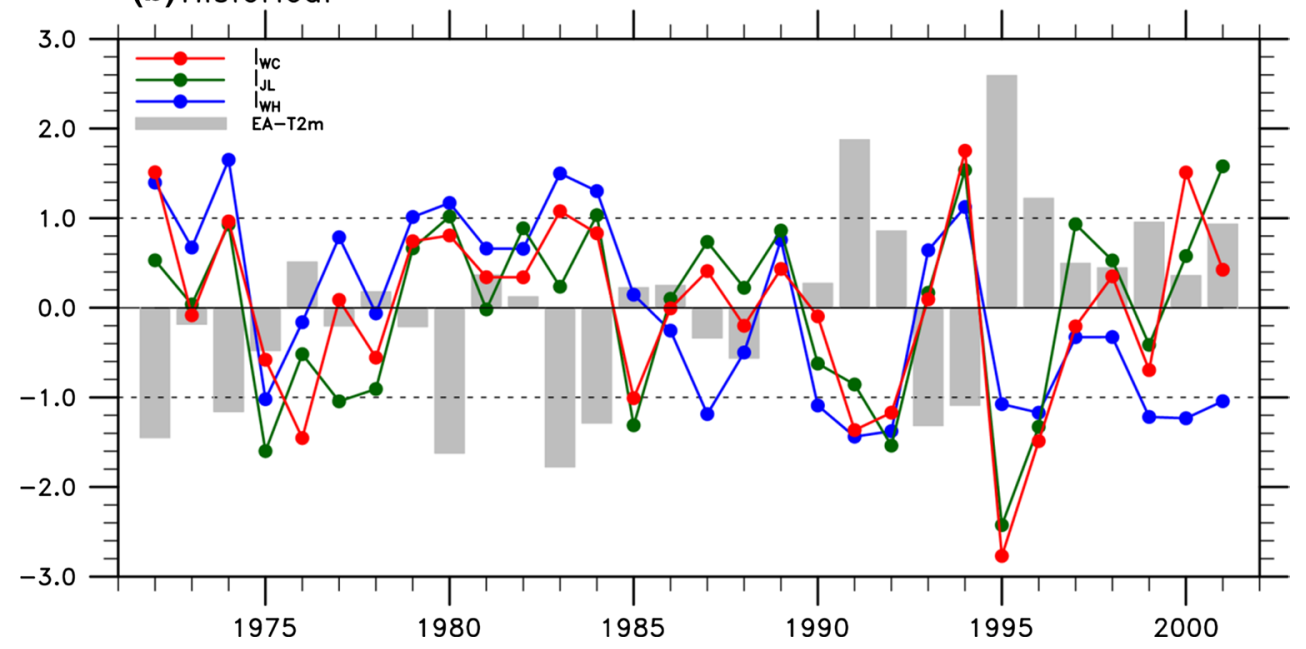

EA and northerly wind anomalies from $\mathrm{SH}$ and $\mathrm{AL}$ are relatively weak compared to observation. The spatial correlations in UV850 are the highest in $\mathrm{I}_{\mathrm{WH}}$ and the lowest in $\mathrm{I}_{\mathrm{WC}}$. Regressed Z500 anomalies onto $\mathrm{I}_{\mathrm{WH}}$ in Historical are the most significant compared to the other EAWMIs, which are similar to observation. In the case of the regressed U300 fields, the jet streams are placed between $30^{\circ} \mathrm{N}$ and $40^{\circ} \mathrm{N}$, which is similar to the position in observation with pattern correlations of above 0.87 in the three EAWMIs. Overall, Historical well captures the EAWMI-related atmospheric anomalies over the whole domain, albeit with systematic errors.

The correlation coefficients among the climatic indices including the EAWMIs for observation and Historical are summarized in Table 3. In observation, the EAWMIs have robust positive (negative) correlations with SH (EA-T2m) (Jhun and Lee 2004; Wang and He 2012; Wang and Chen 2014). $I_{W C}$ shows a weak (strong) negative correlation with $\mathrm{NP}$ (Niño-3.4), whereas $\mathrm{I}_{\mathrm{JL}}$ and $\mathrm{I}_{\mathrm{WH}}$ are strongly (weakly) related with NP (Niño-3.4). The $\mathrm{I}_{\mathrm{WC}}$ and $\mathrm{I}_{\mathrm{WH}}$ have negative relationships with $\mathrm{NAO}$ and $\mathrm{AO}$. The $\mathrm{NAO}$ and $\mathrm{AO}$ are highly correlated because they are two paradigms of one phenomenon (Wallace 2000). The Nino-3.4 has a significant negative correlation with NP in observation. The correlation coefficients between EA-T2m and the other indices except Niño-3.4 are strongly significant. According to Wang and He (2012), the weak correlation between EA-T2m and Niño-3.4 might be related with the diminishment of the significant out-of-phase relationship between EAWM and Niño-3.4 after the 1970s.

Historical generally shows similar teleconnections to observation among the indices (Table 3). Especially, the correlation coefficients between the EAWMIs and climatic indices in Historical are close to those in observation. Although the EAWMIs and AO (Niño-3.4 and NP) relationships in Historical are weaker than those in observation, Historical captures the same negative correlations as observation does. Therefore, Historical reasonably well 
(a) OBS
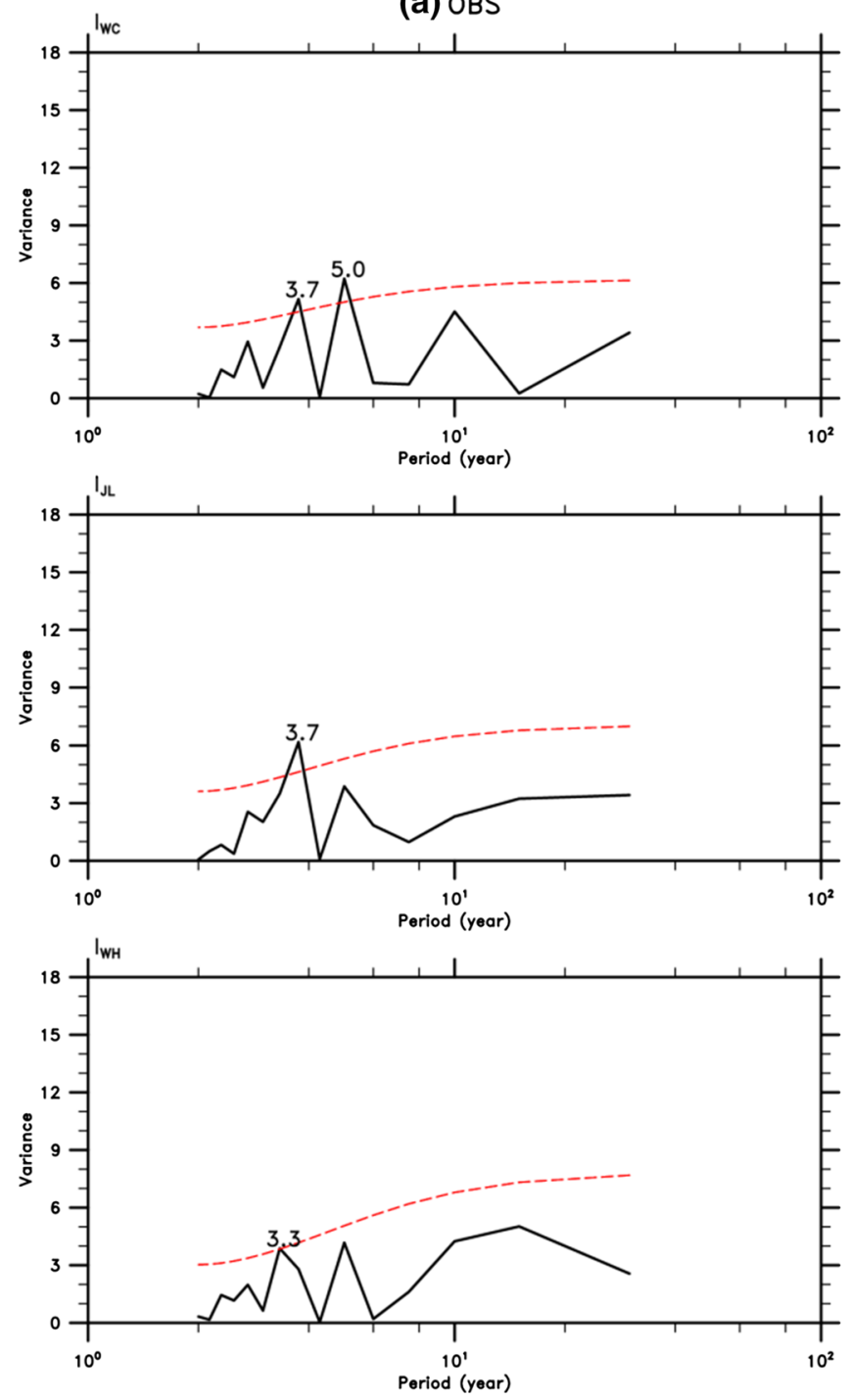

(b) Historical
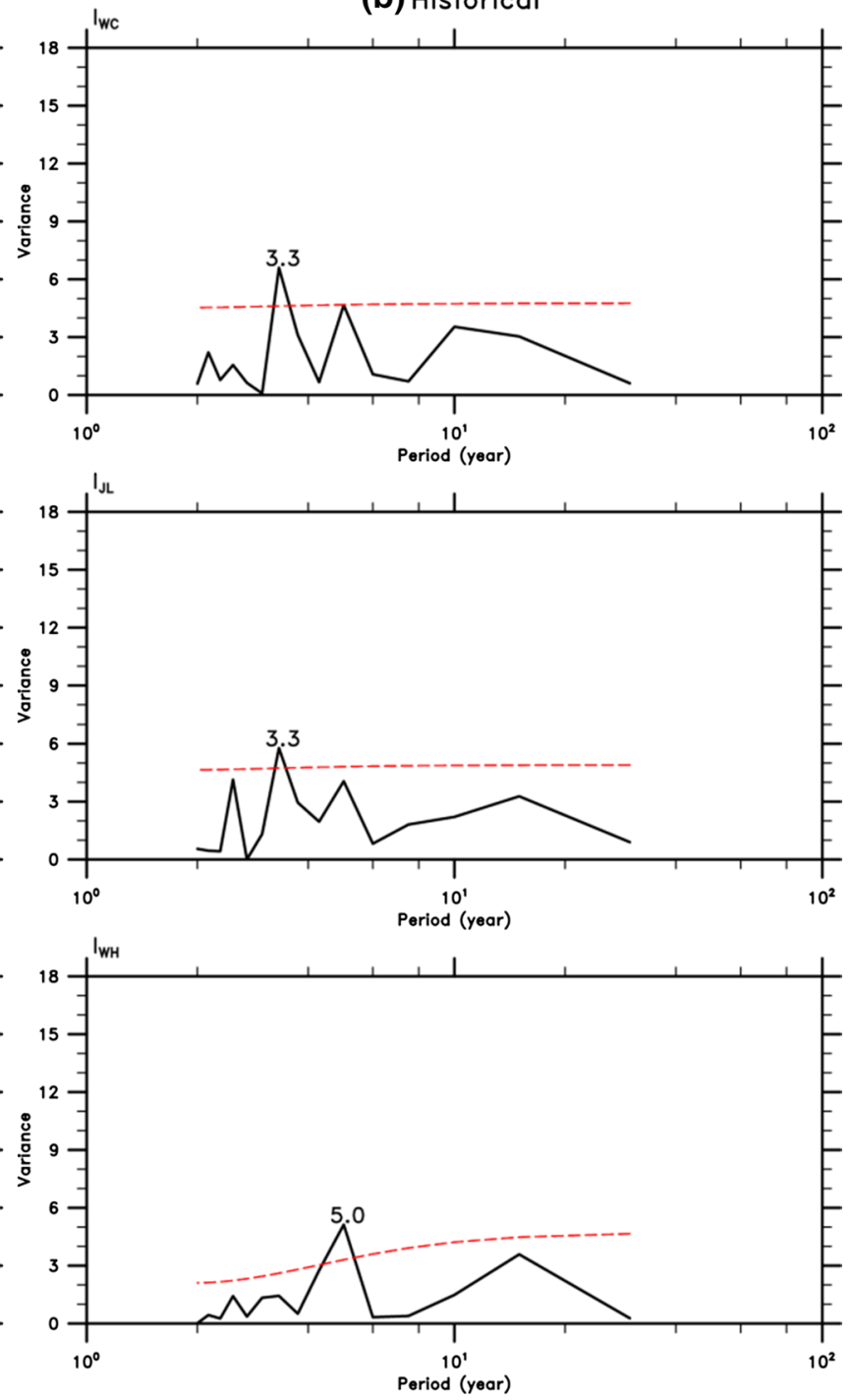

Fig. 3 Power spectra of $\mathrm{I}_{\mathrm{WC}}, \mathrm{I}_{\mathrm{JL}}$, and $\mathrm{I}_{\mathrm{WH}}$ for $\mathbf{a}$ observation and $\mathbf{b}$ Historical. The dashed red lines denote $90 \%$ upper confidence bounds

simulates the teleconnections between the EAWMIs and other climatic indices, as well as the dominant periods of the EAWMIs and characteristic patterns of the fields regressed onto the EAWMIs.

\section{Winter climate changes under RCPs}

The changes in EAWM during the late 21st century under the RCP4.5 and RCP8.5 scenarios are analyzed. The anomaly difference fields between RCPs and Historical over EA for 30-year boreal winters are summarized in Figs. 6 and 7. In RCP4.5, the SLP anomaly in the regions above $40^{\circ} \mathrm{N}$ centered at around the northern NP (central NP area) becomes negative (positive), indicating AL to shift poleward (Fig. 6a). This increases the horizontal pressure gradient between the $\mathrm{SH}$ and $\mathrm{AL}$ regions, but decreases the gradient between the SH and NP regions. Thus, the anomalous southeasterly low-level winds and the anomalous anticyclonic circulations occur over the western NP region, resulting in a weakening of the cold advection by climatological northwesterly winds around the Korean peninsula and south of Japan, in particular, and the anomalous westerly wind around $40^{\circ} \mathrm{N}-45^{\circ} \mathrm{N}$ in the eastern domain (Fig. 6b). That is, near the East Asian coastal region, the northerly is weakened. However, from Lake Baikal to northeast Japan (from the Indo-China Peninsula to the South China Sea), the northwesterly (northeasterly) is intensified.

The surface air temperature is determined by local advection, adiabatic compression/expansion and diabatic processes such as radiative heating and sensible/latent heat 

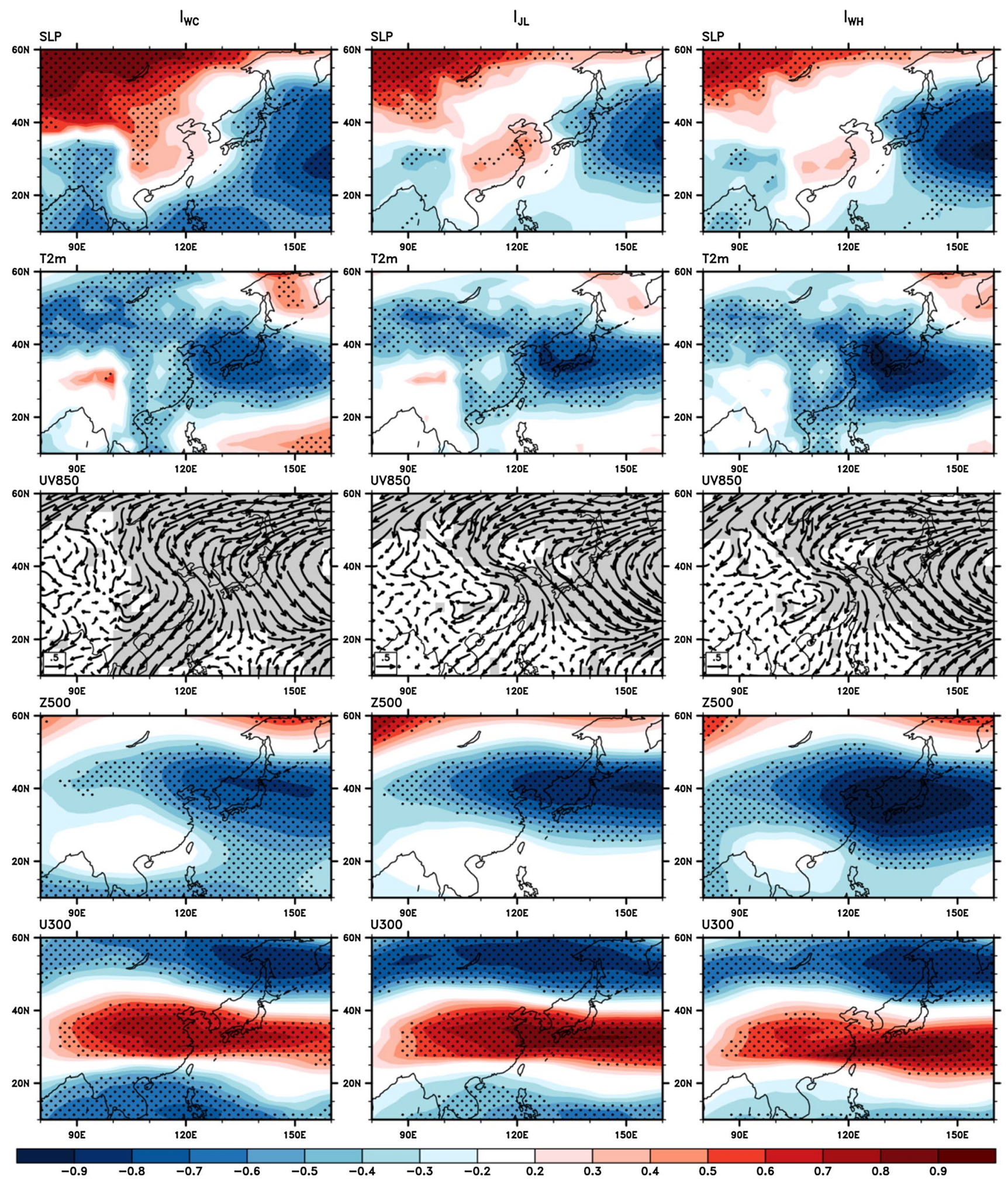

Fig. 4 Fields of DJF-mean atmospheric variables regressed onto the EAWMIs in observation. The grid points exceeding the $95 \%$ confidence level of $t$ test are dotted or shaded with gray 

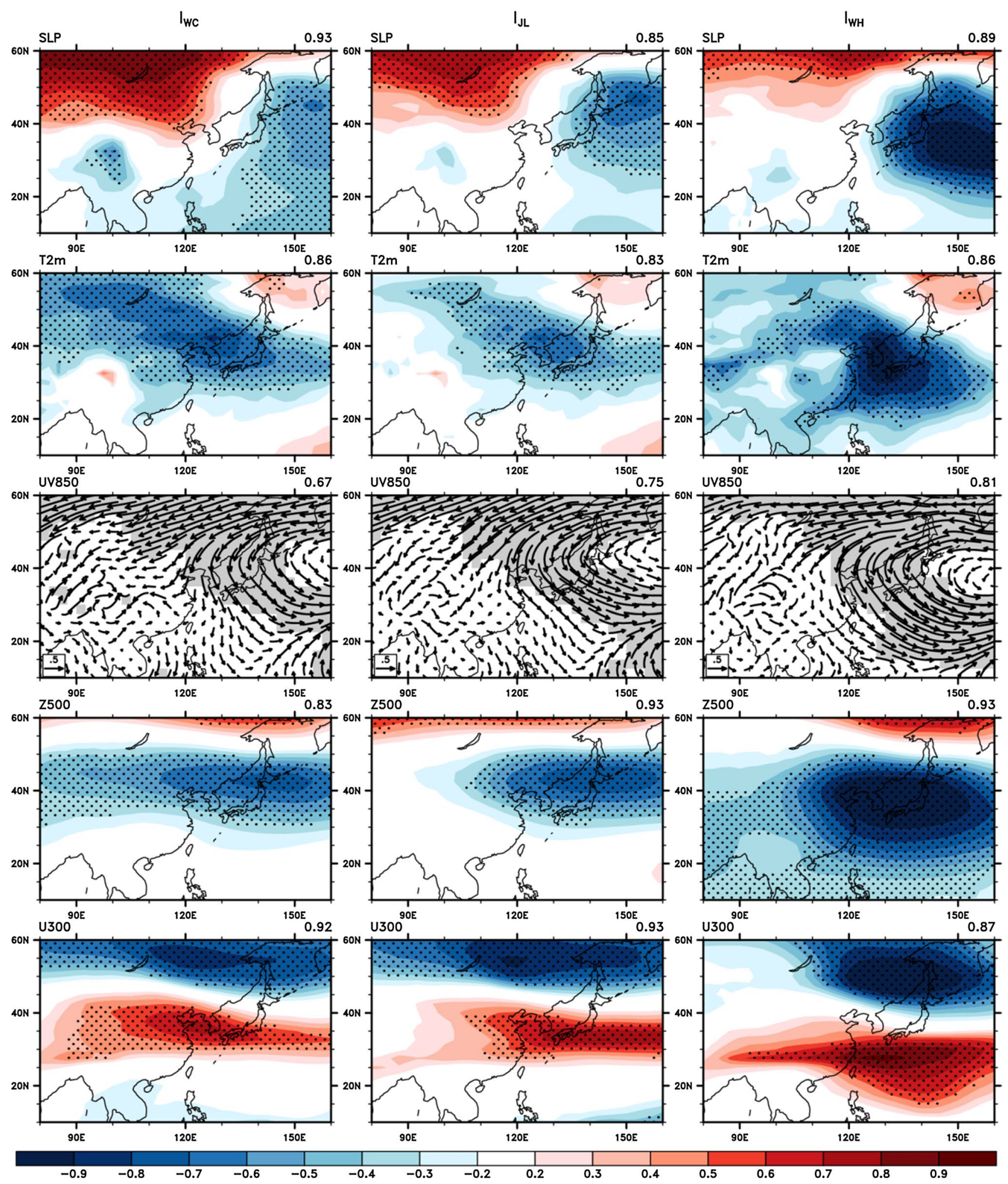

Fig. 5 As in Fig. 4, but for Historical. The upper-right digits are the spatial correlations between observation and model output over the region $10^{\circ} \mathrm{N}-60^{\circ} \mathrm{N}$ and $80^{\circ} \mathrm{E}-160^{\circ} \mathrm{E}$ 
Table 3 Temporal correlation coefficients among climatic indices for observation and Historical

\begin{tabular}{|c|c|c|c|c|c|c|c|c|c|c|}
\hline Data & Index & $\mathrm{I}_{\mathrm{WC}}$ & $\mathrm{I}_{\mathrm{JL}}$ & $\mathrm{I}_{\mathrm{WH}}$ & NP & Niño-3.4 & NAO & SH & $\mathrm{AO}$ & EA-T2 m \\
\hline \multirow[t]{9}{*}{ Observation } & $\mathrm{I}_{\mathrm{WC}}$ & 1.00 & & & & & & & & \\
\hline & $\mathrm{I}_{\mathrm{JL}}$ & $0.74 * *$ & 1.00 & & & & & & & \\
\hline & $\mathrm{I}_{\mathrm{WH}}$ & $0.74 * *$ & $0.80 * *$ & 1.00 & & & & & & \\
\hline & NP & -0.23 & $-0.51 * *$ & $-0.45^{*}$ & 1.00 & & & & & \\
\hline & Niño-3.4 & $-0.49 * *$ & -0.18 & -0.22 & $-0.49 * *$ & 1.00 & & & & \\
\hline & NAO & -0.34 & -0.09 & -0.31 & 0.31 & -0.03 & 1.00 & & & \\
\hline & $\mathrm{SH}$ & $0.91 * *$ & $0.60 * *$ & $0.55 * *$ & -0.16 & -0.34 & -0.21 & 1.00 & & \\
\hline & $\mathrm{AO}$ & $-0.38^{*}$ & -0.27 & $-0.43^{*}$ & $0.39 *$ & -0.08 & $0.71 * *$ & -0.25 & 1.00 & \\
\hline & EA-T2m & $-0.74 * *$ & $-0.69 * *$ & $-0.80 * *$ & $0.38 *$ & 0.19 & $0.45 *$ & $-0.65^{* *}$ & $0.58 * *$ & 1.00 \\
\hline \multirow[t]{9}{*}{ Historical } & $\mathrm{I}_{\mathrm{WC}}$ & 1.00 & & & & & & & & \\
\hline & $\mathrm{I}_{\mathrm{JL}}$ & $0.82 * *$ & 1.00 & & & & & & & \\
\hline & $\mathrm{I}_{\mathrm{WH}}$ & $0.60 * *$ & $0.48^{* *}$ & 1.00 & & & & & & \\
\hline & NP & $-0.36^{*}$ & $-0.44^{*}$ & -0.25 & 1.00 & & & & & \\
\hline & Niño-3.4 & -0.25 & 0.05 & $-0.38^{*}$ & -0.30 & 1.00 & & & & \\
\hline & NAO & -0.28 & -0.15 & -0.33 & 0.11 & -0.22 & 1.00 & & & \\
\hline & $\mathrm{SH}$ & $0.87 * *$ & $0.71 * *$ & $0.39 *$ & -0.27 & -0.05 & -0.24 & 1.00 & & \\
\hline & $\mathrm{AO}$ & -0.25 & -0.23 & -0.36 & 0.14 & -0.06 & $0.46^{*}$ & 0.03 & 1.00 & \\
\hline & EA-T2m & $-0.76 * *$ & $-0.54 * *$ & $-0.75^{* *}$ & $0.42 *$ & 0.16 & $0.40 *$ & $-0.76 * *$ & 0.22 & 1.00 \\
\hline
\end{tabular}

One and two asterisks denote the statistical significance at the 5 and $1 \%$ significance levels, respectively

exchanges between the surface air and earth surfaces. With the increased greenhouse gases, the surface air temperature is deemed to increase in the long-term with a larger increment in the higher latitude. Relatively large warming of $\mathrm{T} 2 \mathrm{~m}$ in the higher latitude is attributed to feedbacks associated with changes in snow cover and sea ice (Serreze et al. 2007; Comiso et al. 2008; Soden et al. 2008; Graversen and Wang 2009; Kumar et al. 2010). Also the horizontal transport of globally increased latent heat into the Arctic is also known to induce the enhanced warming near the poles (Alexeev et al. 2005; Cai 2005; Langen and Alexeev 2007; Kug et al. 2010), which is mainly confined in the lower layer of the atmosphere since the air is statistically stable in the higher latitude. Such latitudinal distributions of T2m are also shown in Fig. 6c. Figure 6d shows the net total radiation at the surface (downward positive). According to the figure, the positive net surface radiative heating is widely spread throughout the whole domain during the boreal winter, except around the Heilongjiang region in China. The relatively large positive regions are zonally distributed around $20^{\circ} \mathrm{N}-40^{\circ} \mathrm{N}$, centered at around the South China Sea. The positive net radiation at the surface is mainly due to the decrease of cloudiness over the area (Fig. 6e), as inferred from the spatial patterns of the two variables which are similar. According to the net sensible and latent heat fluxes at the surface (downward positive) (Fig. 6f), there is relatively large net positive (negative) heating in the south of Japan (East Sea/Sea of Japan and Sea of Okhotsk). Thus, in addition to the latitudinal
Fig. 6 Differences in DJF-mean climatological fields (2070/712099/100) of a sea level pressure, b 850 -hPa winds, c temperature at 2-m height, $\mathbf{d}$ net total surface radiation (downward positive), e cloudiness, $\mathbf{f}$ net surface latent and sensible heat fluxes (downward positive), g 500-hPa geopotential height, and $\mathbf{h}$ 300-hPa zonal wind speed between RCP4.5 and Historical (blue/red shadings and red arrows). Contours and black arrows denote the climatology of Historical. The grid points exceeding the $95 \%$ confidence level of $t$ test are dotted or shaded in gray

increase of $\mathrm{T} 2 \mathrm{~m}$ described above, the relatively large increase of $\mathrm{T} 2 \mathrm{~m}$ over the Korean Peninsula, southern part of Japan and eastern and southern parts of China (Fig. 6c) may be, to some extent, attributed to the anomalous warm temperature advection associated with the anomalous low level wind from the region of increased radiative heating and increased net surface latent and sensible heat fluxes.

The increase of lower level temperature induces the thickness increase (Fig. 6g). The increase of Z500 is more significant at the central region (particularly in the eastern edge) of the analysis domain. As a result, meridional gradients of pressure and $\mathrm{T} 2 \mathrm{~m}$ are increased and decreased at the northern and southern regions of the domain, respectively. Consequently, EAWM in RCP4.5 is diminished at the southern region of the domain compared to Historical, resulting in the northward movement of the jet stream (Fig. 6h) due to the changes of meridional temperature gradient.

In RCP8.5, the SLP change is similar to the change in RCP4.5 (Figs. 6a and 7a), except for the more decreased 
(a) SLP

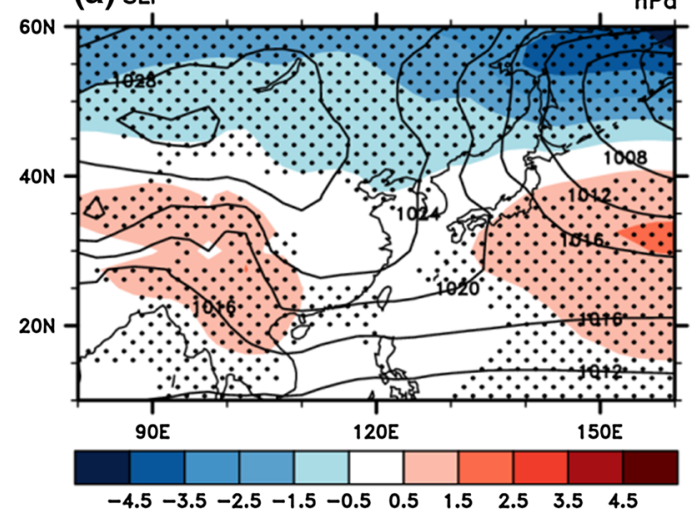

(c) $\mathrm{T} 2 \mathrm{~m}$

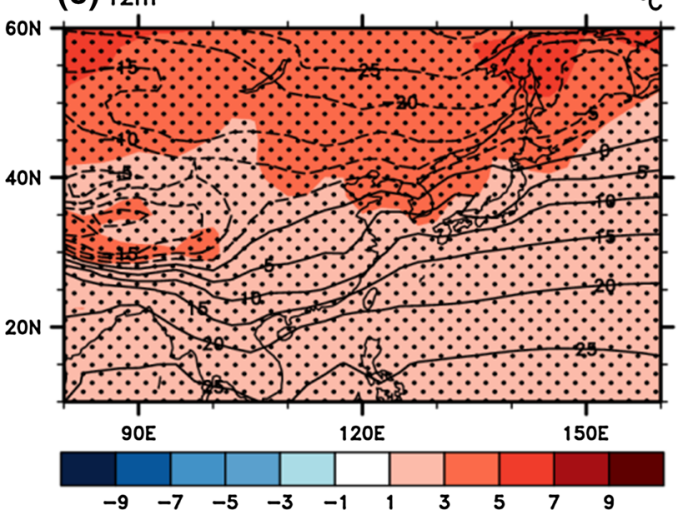

(b) UV850

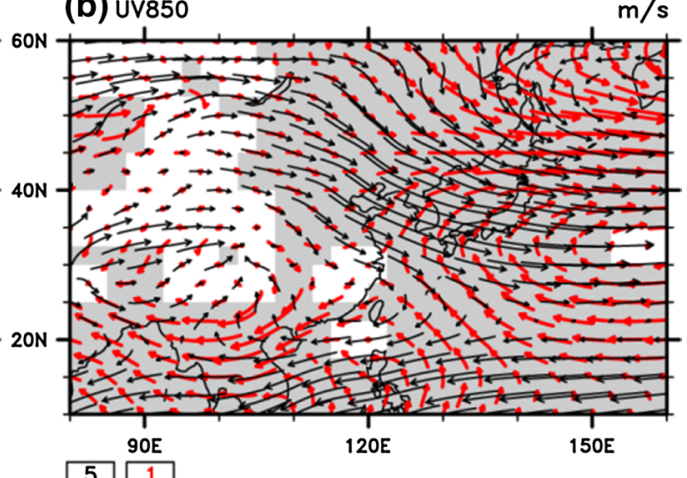

$\stackrel{5}{\longrightarrow} \stackrel{1}{\longrightarrow}$

(d) Net radiative budget
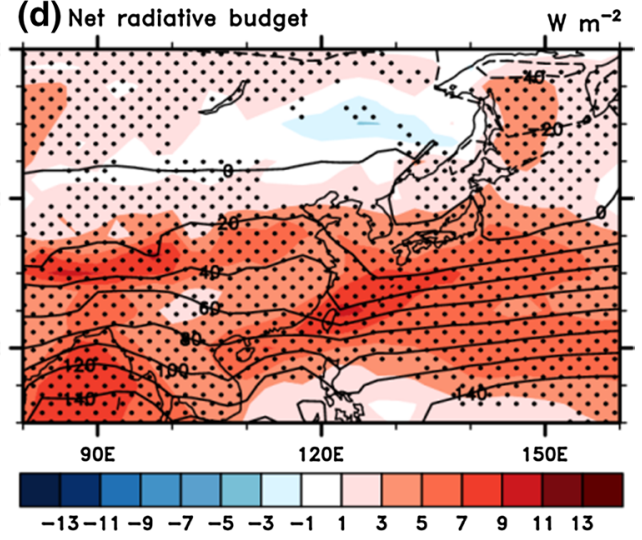

(f) $\mathrm{SH}+\mathrm{LH}$
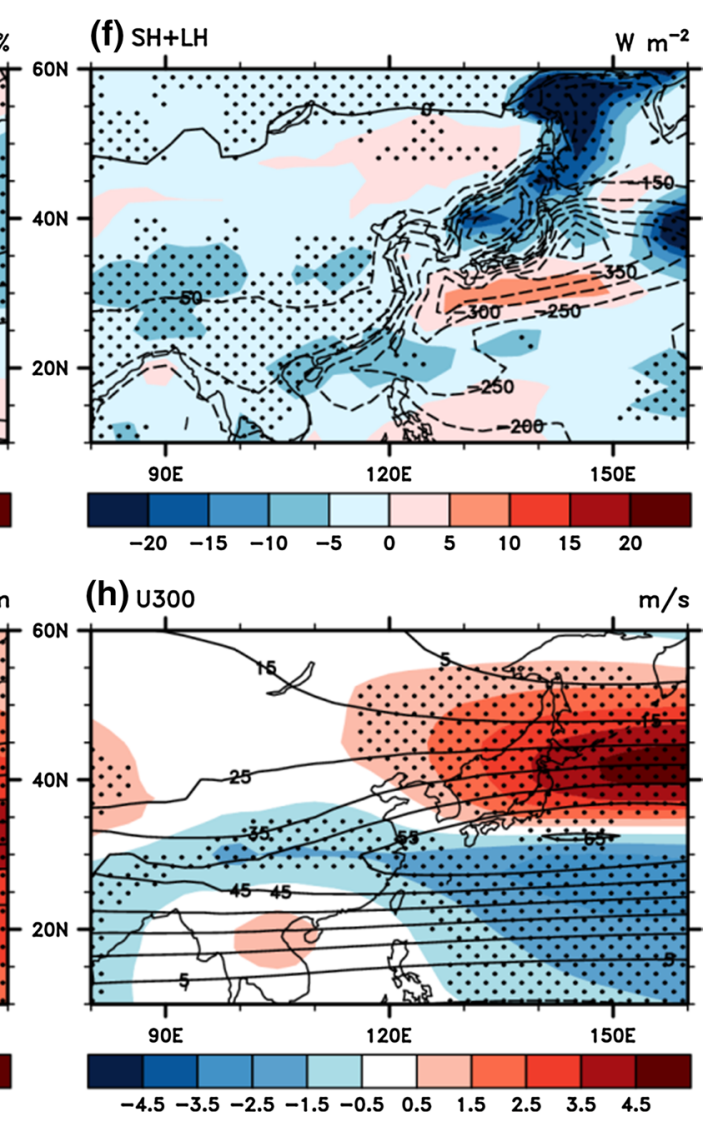

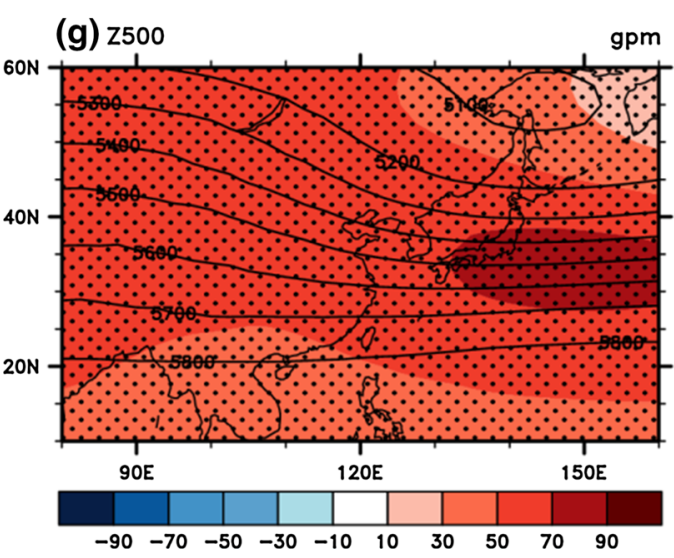


(a) SLP

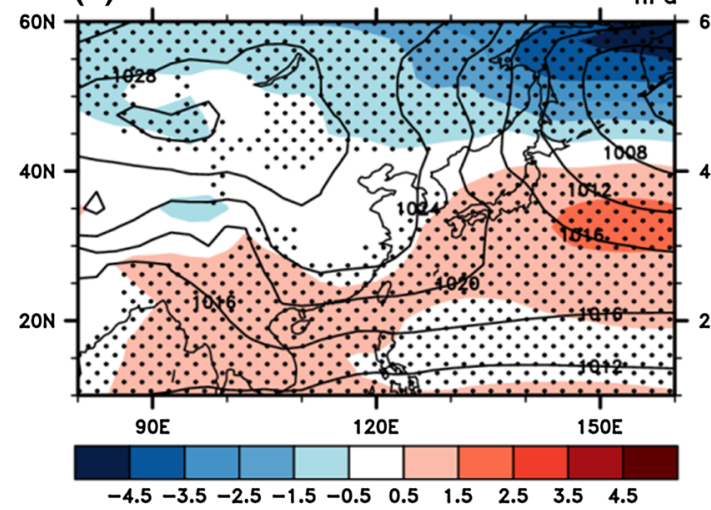

(c) $\mathrm{T} 2 \mathrm{~m}$

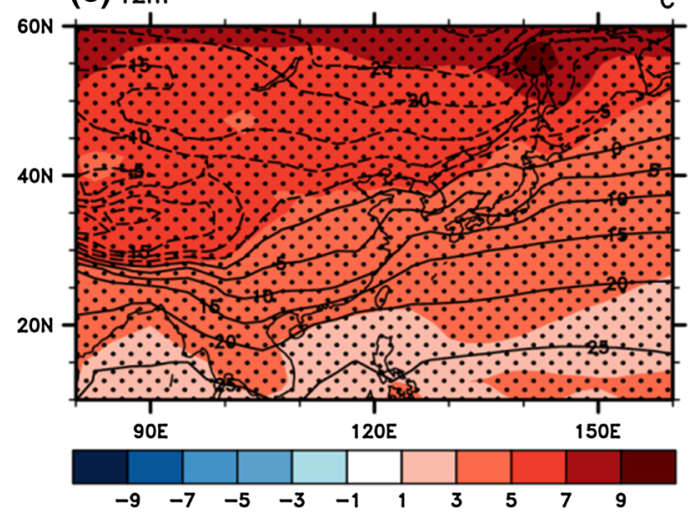

(e) Cloud

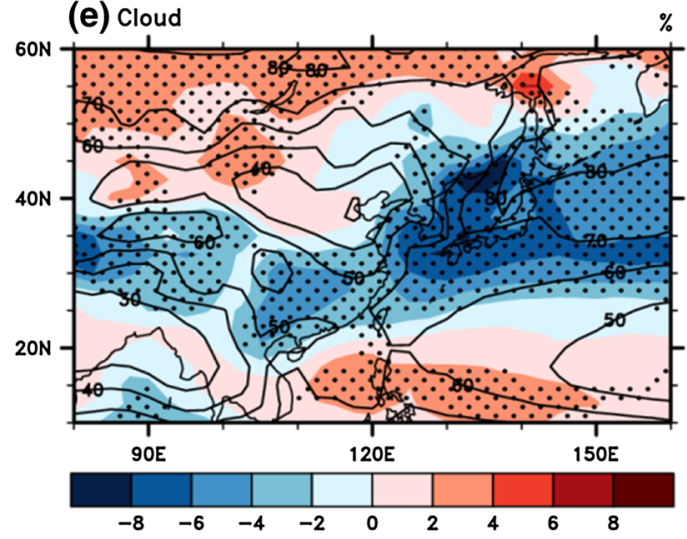

(g) 2500

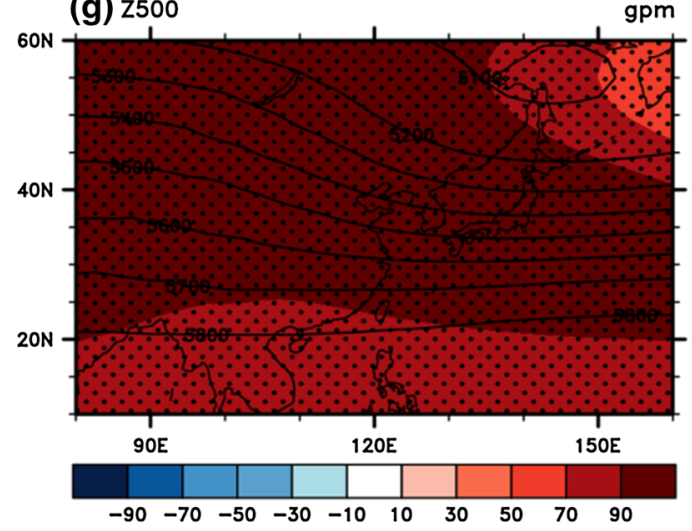

(b) Uv850

$\mathrm{m} / \mathrm{s}$

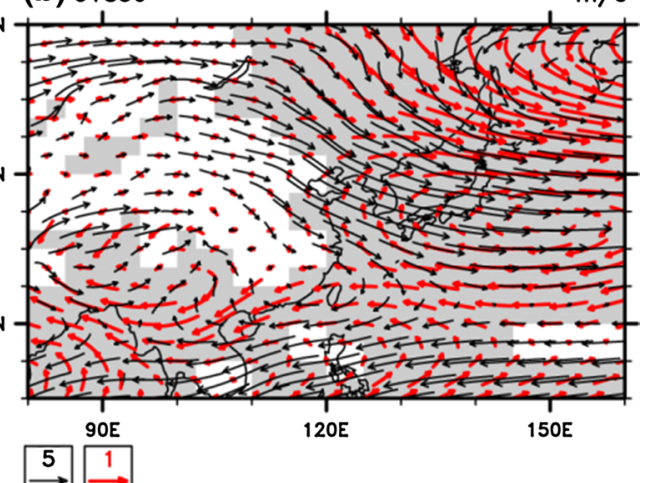

$\stackrel{5}{\longrightarrow} \stackrel{1}{\longrightarrow}$

(d) Net radiative budget

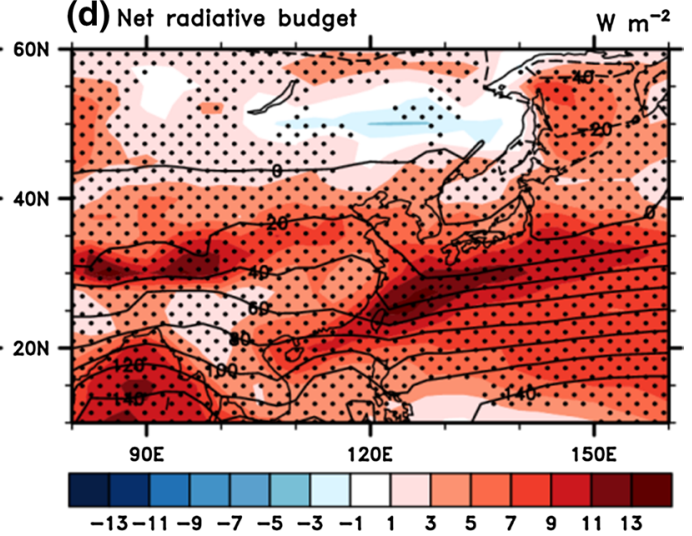

(f) $\mathrm{SH}+\mathrm{LH}$
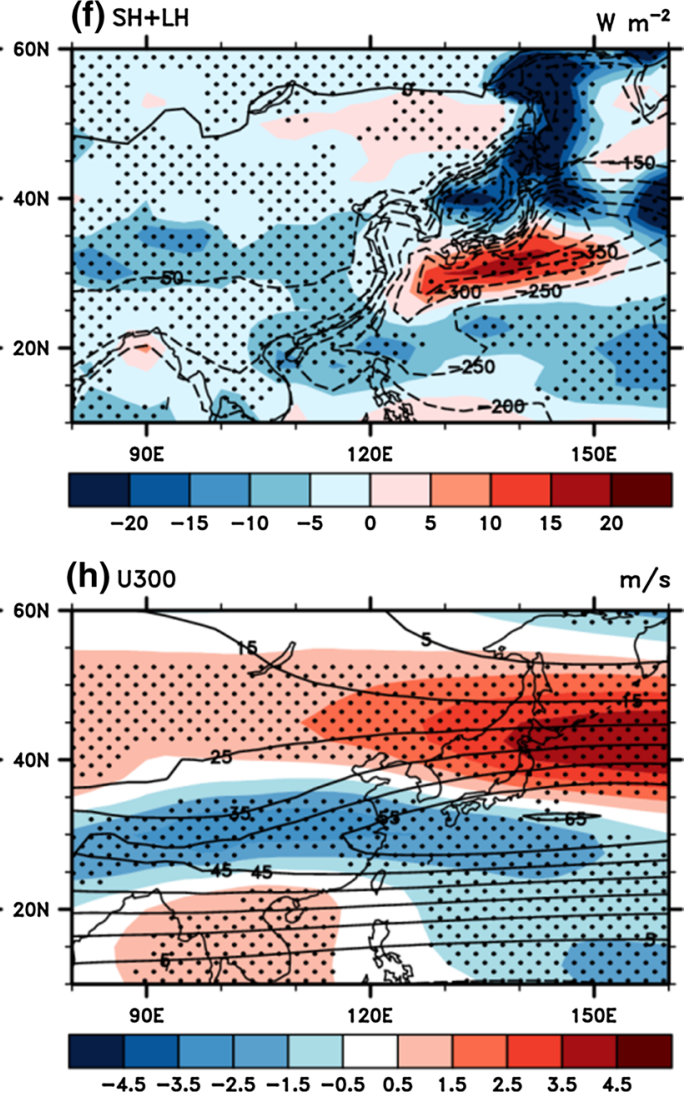

Fig. 7 As in Fig. 6, but for the differences between RCP8.5 and Historical 
Fig. 8 As in Fig. 2, but for a RCP4.5 and b RCP8.5 for the period 2005/06-2099/100, including Historical for the period 1971/72-2004/05 (a) RCP 4.5

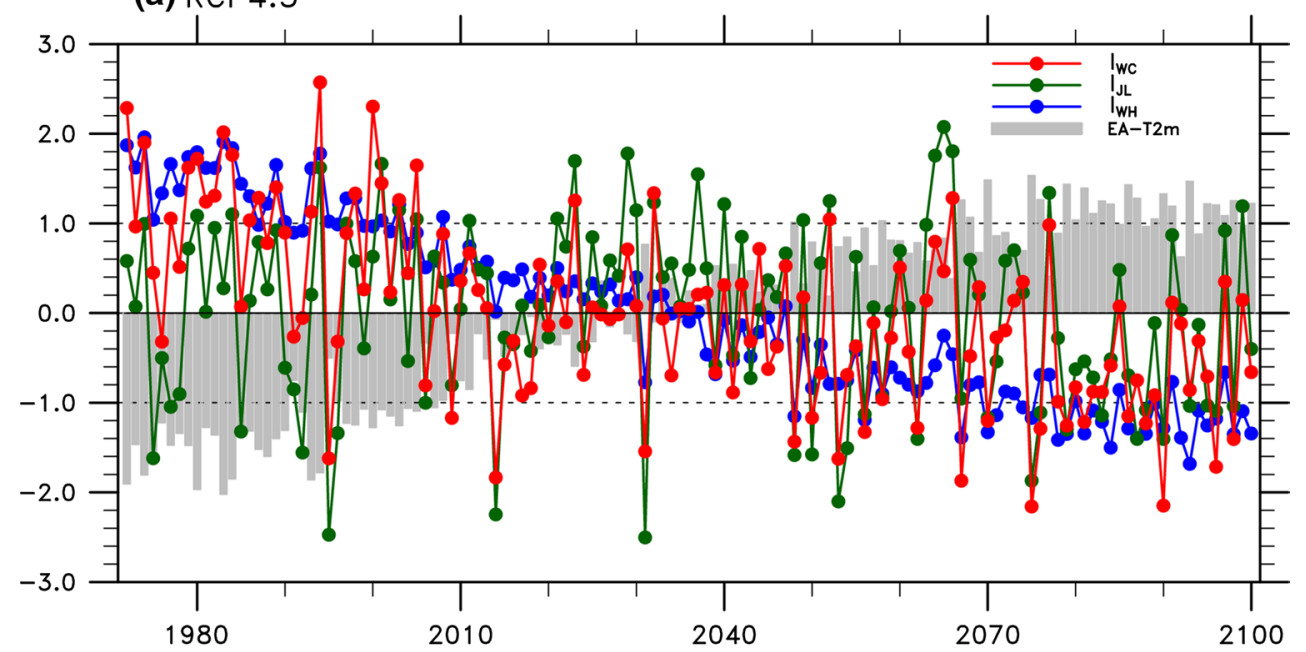

(b) RCP8.5

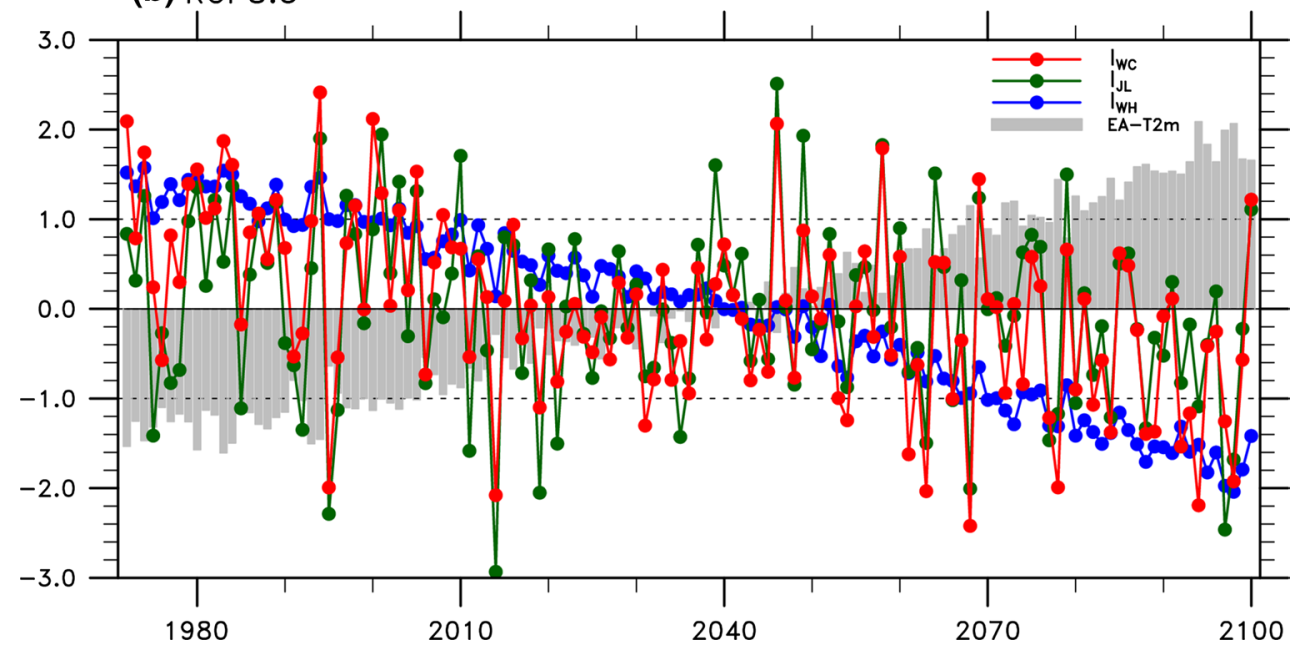

(increased) horizontal pressure gradient between $\mathrm{SH}$ and $\mathrm{NP}$ (SH and AL). The differences in T2m (Figs. $6 \mathrm{c}$ and $7 \mathrm{c}$ ) and Z500 (Figs. $6 \mathrm{~g}$ and $7 \mathrm{~g}$ ) between RCP4.5 and RCP8.5 are more prominent compared to the other variables. The warming in $\mathrm{T} 2 \mathrm{~m}$ is generally significant over the north region compared to the south region in the domain. $T 2 \mathrm{~m}$ and Z500 increase by more than $2{ }^{\circ} \mathrm{C}$ and 40 gpm, respectively, in most of the domain compared to RCP4.5. Thus, the EA trough in RCP8.5 is projected to be weakened more than in RCP4.5. In addition, the anomalous southeasterly winds over the over the Korean Peninsula, southern part of Japan and eastern China are slightly stronger than those in RCP4.5 (Fig. 7b). For U300, the changes in RCP4.5 are distinct over the NP region, where as those in RCP8.5 increase to the north of $35^{\circ} \mathrm{N}$ and decrease between $20^{\circ} \mathrm{N}$ and $35^{\circ} \mathrm{N}$ in the eastern domain (Figs. $6 \mathrm{~h}$ and $7 \mathrm{~h}$ ). The weakening of the jet stream in both RCPs is attributed directly to the increased thickness and temperature in the middle troposphere because the meridional temperature gradient is weakened due to the enhanced warming over the northern region in $\mathrm{T} 2 \mathrm{~m}$. Overall, such changes are more pronounced in RCP8.5 than in RCP4.5, including net total radiation (Figs. 6d and 7d) and net surface latent and sensible heat fluxes (Figs. 6f and 7f).

Figure 8 shows the time series of normalized anomalies of the EAWMIs and EA-T2m under RCP4.5 and RCP8.5, including Historical, during the boreal winter. The time series for RCP4.5 demonstrate decreasing trends in the EAWMIs at a rate of $-0.015 /$ year in $\mathrm{I}_{\mathrm{WC}},-0.004$ / year in $\mathrm{I}_{\mathrm{JL}}$, and $-0.026 /$ year in $\mathrm{I}_{\mathrm{WH}}$, and an increasing trend in EA-T2m at a rate of 0.025/year (Fig. 8a) during 1971/72-2099/100. These are significant at the $5 \%$ significance level except for $\mathrm{I}_{\mathrm{JL}}$. Compared to Historical, 30-year averages of the EAWMIs and EA-T2m are decreased and increased, respectively. The 30-year average differences between RCP4.5 and Historical (RCP4.5 minus Historical) are -1.67 in $\mathrm{I}_{\mathrm{WC}},-0.42$ in $\mathrm{I}_{\mathrm{JL}},-2.54$ in $\mathrm{I}_{\mathrm{WH}}$, and 2.50 in EA-T2m. The larger the negative value, the weaker the 
(a) RCP4.5
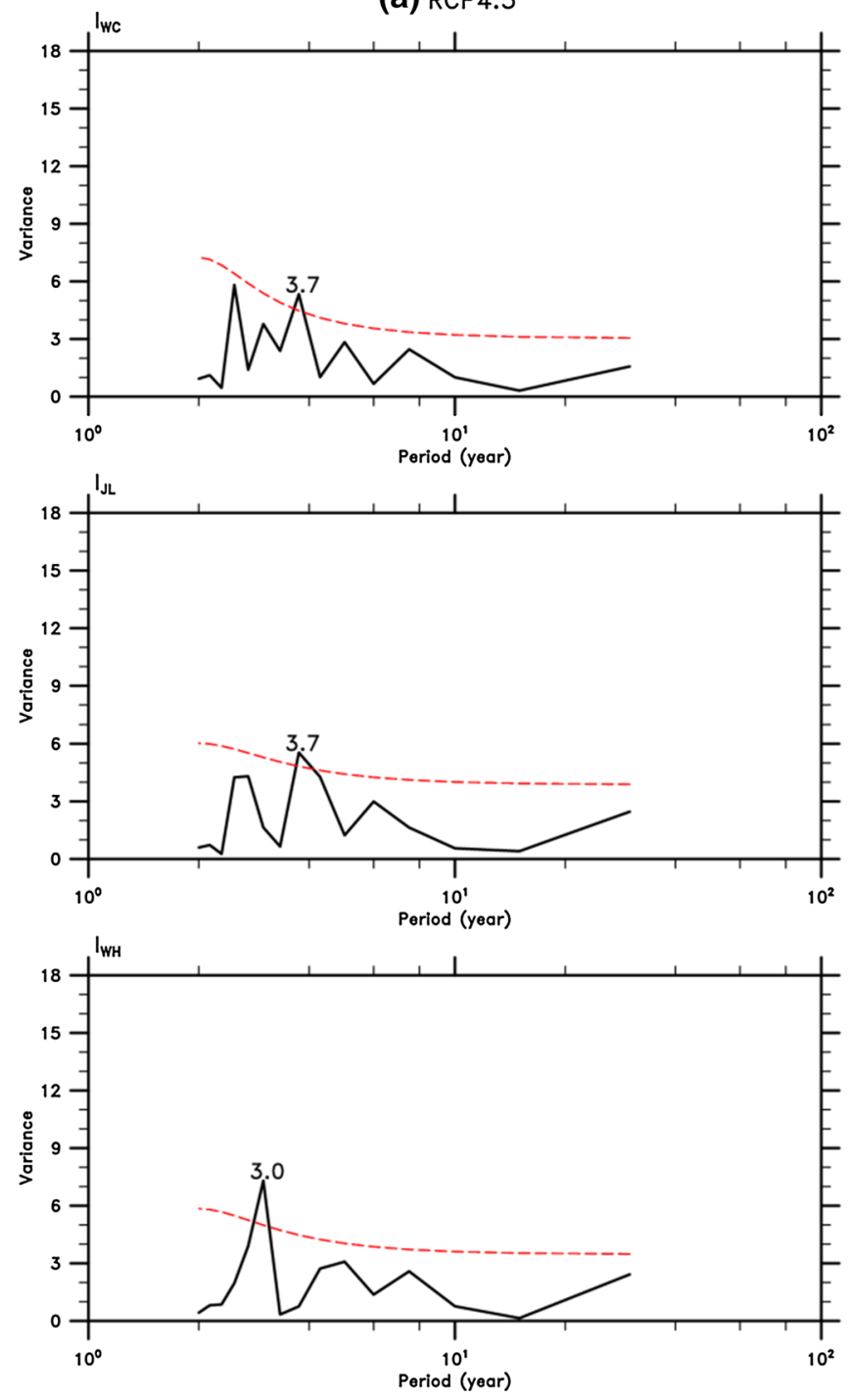

Fig. 9 As in Fig. 3, but for a RCP4.5 and b RCP8.5

EAWM and the warmer winter in EA in terms of EAWMI and EA-T2m, respectively. These all negative values indicate that EAWM and winter temperature in RCP4.5 will become weaker and warmer than those in Historical, respectively. Weak monsoons and warm EA-T2m based on the $-1.0 \mathrm{SD}$ for the EAWMIs and 1.0 SD for EA-T2m of each index are clearly increased in RCP4.5; while strong monsoons (above 1.0 SD) during 2070/71-2099/100 occur only twice in $\mathrm{I}_{\mathrm{JL}}$ and do not occur in either $\mathrm{I}_{\mathrm{WC}}$ or $\mathrm{I}_{\mathrm{WH}}$, and cold EA-T2m is not projected below $-1.0 \mathrm{SD}$. Thus, the years of weak monsoon well match with those of warm EA-T2 $m$ in the projection.

In RCP8.5, for 129 years, $\mathrm{I}_{\mathrm{WC}}(-0.013 /$ year $), \mathrm{I}_{\mathrm{JL}}$ $(-0.005 /$ year $)$, and $\mathrm{I}_{\mathrm{WH}}(-0.026 /$ year $)$ all exhibit decreasing trends that are significant at the $5 \%$ significance level (b) RCP8.5
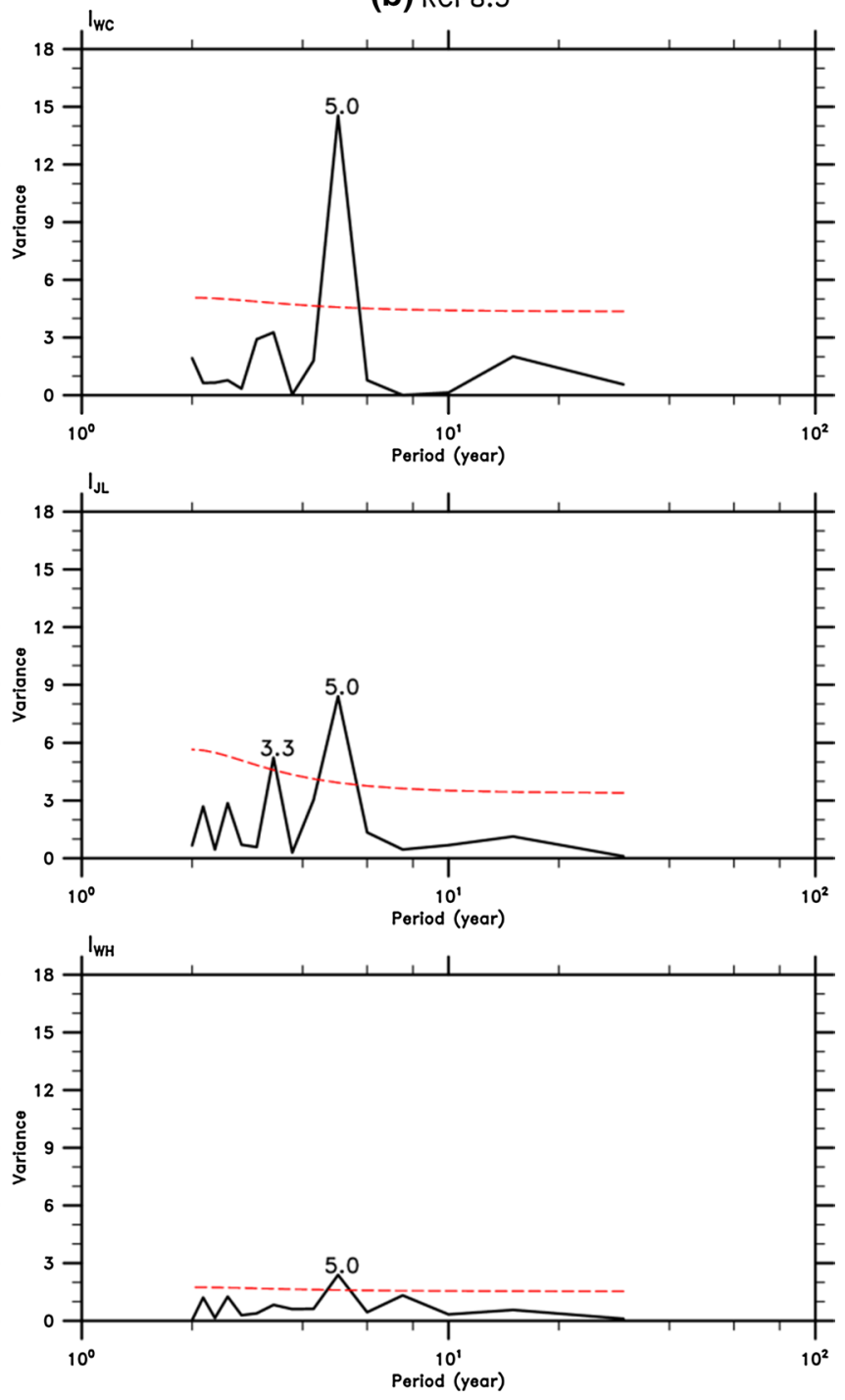

(Fig. 8b). In the case of EA-T2m, the trend (0.026/year) is significantly increasing as in RCP4.5. The 30-year mean differences of the EAWMIs between RCP8.5 and Historical (RCP8.5 minus Historical) are -1.36 in $\mathrm{I}_{\mathrm{WC}},-0.57$ in $\mathrm{I}_{\mathrm{JL}}$, and -2.63 in $\mathrm{I}_{\mathrm{WH}}$, and that of EA-T2m is 2.62 . The absolute values of these results are larger than the differences between RCP4.5 and Historical except for $\mathrm{I}_{\mathrm{WC}}$, which implies that the stronger global warming induces the weaker winter monsoon and the warmer winter. The numbers of weak monsoon years and warm EA-T2m years increase over time with larger rate than RCP4.5.

The major peak periods of $\mathrm{I}_{\mathrm{WC}}$ and $\mathrm{I}_{\mathrm{JL}}$ based on RCP4.5 and RCP8.5 are similar (3.7 year) and longer (5.0 year) than that based on Historical, respectively (Fig. 9). The peak periods of the two indices in RCP4.5 and RCP8.5 are 

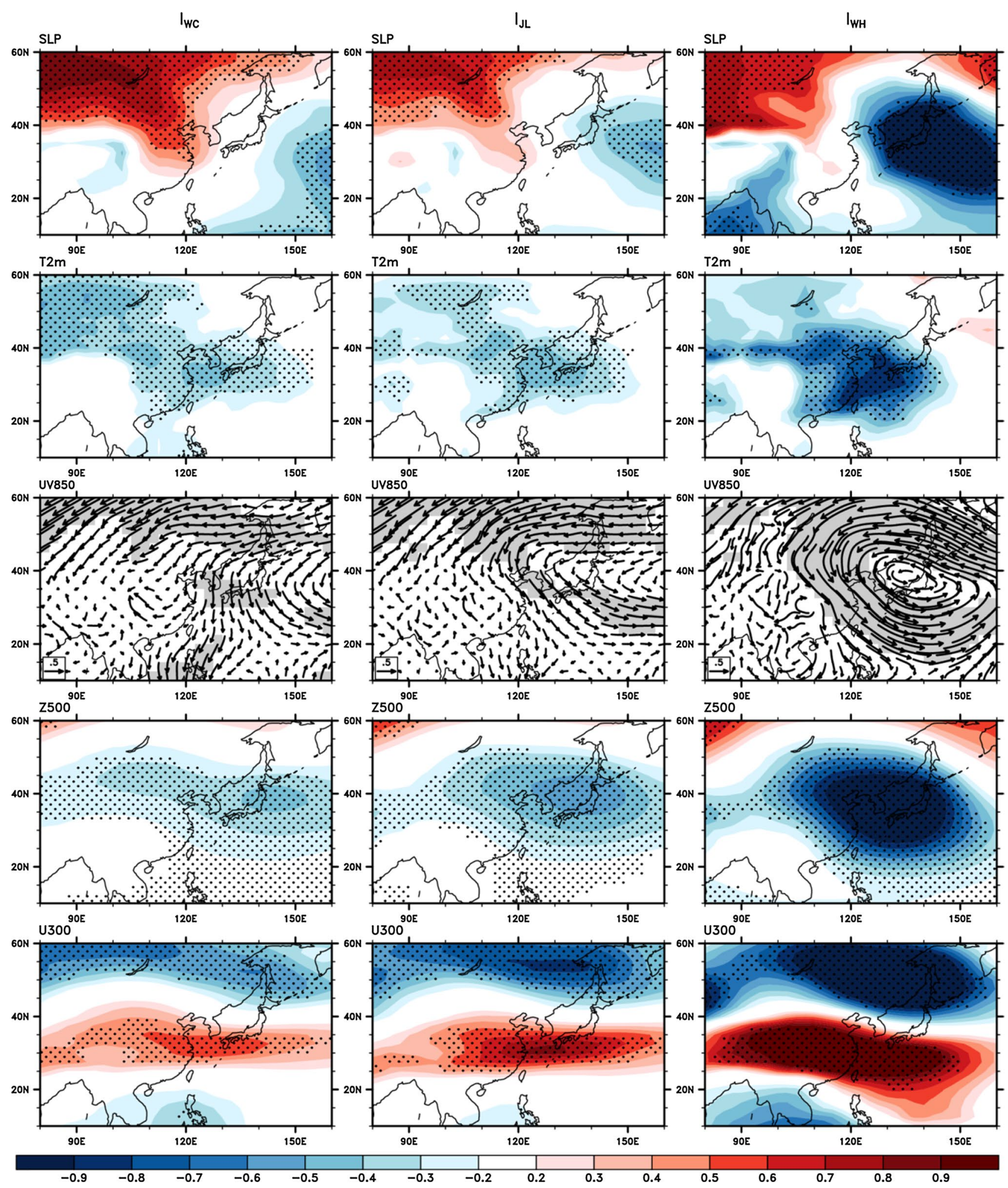

Fig. 10 As in Fig. 4, but for RCP8.5

significant at the 10 and $5 \%$ significance levels, respectively. In the case of $\mathrm{I}_{\mathrm{WH}}$, the dominant periods are 3.0 year in RCP4.5, which is shorter than that in Historical, and
5.0 year in RCP8.5, which is the same as that in Historical. Compared to Historical, the interannual components in the EAWMIs are predominant but the interdecadal components 
Table 4 As in Table 3, but for RCPs

\begin{tabular}{|c|c|c|c|c|c|c|c|c|c|c|}
\hline Data & Index & $\mathrm{I}_{\mathrm{WC}}$ & $\mathrm{I}_{\mathrm{JL}}$ & $\mathrm{I}_{\mathrm{WH}}$ & $\mathrm{NP}$ & Niño-3.4 & NAO & $\mathrm{SH}$ & $\mathrm{AO}$ & EA-T2m \\
\hline \multirow[t]{9}{*}{ RCP4.5 } & $\mathrm{I}_{\mathrm{WC}}$ & 1.00 & & & & & & & & \\
\hline & $\mathrm{I}_{\mathrm{JL}}$ & $0.86 * *$ & 1.00 & & & & & & & \\
\hline & $\mathrm{I}_{\mathrm{WH}}$ & $0.46^{*}$ & $0.60 * *$ & 1.00 & & & & & & \\
\hline & $\mathrm{NP}$ & $-0.43^{*}$ & $-0.44^{*}$ & -0.05 & 1.00 & & & & & \\
\hline & Niño-3.4 & -0.06 & 0.01 & -0.04 & -0.31 & 1.00 & & & & \\
\hline & NAO & -0.27 & -0.30 & $-0.39 *$ & $0.56 * *$ & $-0.39 *$ & 1.00 & & & \\
\hline & $\mathrm{SH}$ & $0.85^{* *}$ & $0.66 * *$ & 0.20 & $-0.43^{*}$ & 0.16 & -0.31 & 1.00 & & \\
\hline & $\mathrm{AO}$ & $-0.50 * *$ & $-0.50 * *$ & $-0.51 * *$ & $0.50 * *$ & -0.30 & $0.82 * *$ & $-0.45^{*}$ & 1.00 & \\
\hline & EA-T2m & $-0.76 * *$ & $-0.70 * *$ & $-0.42 *$ & $0.38 *$ & -0.28 & $0.51 * *$ & $-0.81 * *$ & $0.62 * *$ & 1.00 \\
\hline \multirow[t]{9}{*}{ RCP8.5 } & $\mathrm{I}_{\mathrm{WC}}$ & 1.00 & & & & & & & & \\
\hline & $\mathrm{I}_{\mathrm{JL}}$ & $0.82 * *$ & 1.00 & & & & & & & \\
\hline & $\mathrm{I}_{\mathrm{WH}}$ & $0.45 *$ & $0.62 * *$ & 1.00 & & & & & & \\
\hline & $\mathrm{NP}$ & -0.33 & -0.33 & -0.02 & 1.00 & & & & & \\
\hline & Niño-3.4 & -0.34 & -0.35 & $-0.70 * *$ & -0.07 & 1.00 & & & & \\
\hline & NAO & -0.01 & -0.05 & -0.15 & -0.02 & -0.21 & 1.00 & & & \\
\hline & SH & $0.86^{* *}$ & $0.70 * *$ & 0.36 & -0.21 & -0.05 & -0.13 & 1.00 & & \\
\hline & $\mathrm{AO}$ & $-0.39 *$ & $-0.46^{*}$ & $-0.51 * *$ & 0.19 & 0.12 & $0.63 * *$ & $-0.41 *$ & 1.00 & \\
\hline & EA-T2m & $-0.45^{*}$ & $-0.52 * *$ & $-0.88 * *$ & 0.06 & $0.59 * *$ & 0.26 & $-0.48^{* *}$ & $0.63 * *$ & 1.00 \\
\hline
\end{tabular}

are not significant in either RCP. That is, the period of EAWM except for $\mathrm{I}_{\mathrm{WH}}$ is projected to increase in RCPs compared to Historical.

Figure 10 shows regression maps of winter atmospheric variable anomalies with respect to the EAWMIs under RCP8.5. The patterns of regressed fields in RCP4.5 are not shown because those in RCP8.5 and RCP4.5 are similar with each other. The fields of SLP, T2m, and UV850 regressed onto the EAWMIs in RCP8.5 are slightly shifted northwestward compared to those in Historical in Fig. 5. Compared to Historical, the locations of $\mathrm{SH}, \mathrm{AL}$ and the center of the low-level circulation over the northwestern Pacific are moved more poleward, the T2m becomes less cold, and the EA trough is generally weakened. The field of SLP (T2m) regressed onto $\mathrm{I}_{\mathrm{WC}}\left(\mathrm{I}_{\mathrm{WH}}\right)$ is significant over the $\mathrm{SH}$ region (north to $30^{\circ} \mathrm{N}$ ) compared to the other fields of SLP (T2m) regressed onto the other two EAWMIs. All the regressed fields of T2m over EA are warmer than Historical, indicating a warm winter in RCP8.5. The northerly winds at $850 \mathrm{hPa}$ are also weakened over the domain. In addition, the fields of Z500 regressed with respect to $\mathrm{I}_{\mathrm{WC}}$ and $\mathrm{I}_{\mathrm{JL}}$ are decreased compared to Historical. The jet stream at $300 \mathrm{hPa}$ is weakened, particularly in the fields of $\mathrm{U} 300$ regressed onto $\mathrm{I}_{\mathrm{WC}}$ and $\mathrm{I}_{\mathrm{JL}}$.

Table 4 illustrates the reduced (enhanced) correlation between the EAWMIs and Niño-3.4 (AO) in RCP4.5 compared to Historical. The relationship between the EAWMIs except for $\mathrm{I}_{\mathrm{WH}}$ and NP is increased, and between the EAWMIs and NAO tends to be reinforced in RCP4.5. The negative correlation between EA-T2m and $\mathrm{AO}$ is significant at the $5 \%$ significance level. The relationship between the EAWMIs except for $\mathrm{I}_{\mathrm{WH}}$ and SH (EA-T2m) remains strong. Compared to Historical, the teleconnection between $\mathrm{NP}$ and other climatic indices except for $\mathrm{I}_{\mathrm{WH}}$ tends to be increased. The positive correlation between $\mathrm{AO}$ and $\mathrm{SH}$ is also significantly enhanced.

In RCP8.5, the correlation between the EAWMIs is as strong as in Historical and RCP4.5 (Table 4). Different from RCP4.5, the relationship between EAWM and NP is decreased compared to Historical. In addition, the negative correlation between EAWM and Niño-3.4 is enhanced, especially in $\mathrm{I}_{\mathrm{WH}}$. There is almost no correlation between EAWM and NAO in RCP8.5. Similar to Historical and RCP4.5, EAWM is strongly related with $\mathrm{SH}$ and EA-T2m. The teleconnection between EAWM and AO is increased in RCP8.5 compared to Historical. For NAO, the correlation coefficient with AO remains strong, but that with EA-T2m is reduced. The relationship of EA-T2m with AO is significantly increased compared to Historical (not to RCP4.5).

\section{Discussion and summary}

The boreal winter climate changes have been projected under RCP4.5 and RCP8.5. The changes of climatology, interannual variations, and regressed fields have been analyzed in terms of the EAWMIs. For this, nine climate models were selected based on pattern correlations with observation in terms of EOF from SLP and T2m. Then, MME was applied to these model outputs. In addition, the three 
EAWMIs that had robust temporal correlations with EA$\mathrm{T} 2 \mathrm{~m}$ in both observation and CMIP5 were used for the further analysis.

This study firstly analyzes the performance of climate models from CMIP5 in simulating the boreal winter circulation over EA using the EAWMIs. Although the simulated DJF mean fields exhibit some biases over EA, the general patterns in Historical are similar to those in observation. The negative matching between the EAWMIs and EA$\mathrm{T} 2 \mathrm{~m}$ are well reproduced. Power spectral analyses of the simulated indices exhibit an interannual variability with major peaks occurring in 3-5 years, as in the observation. The fields regressed onto the EAWMIs, which resemble the composite of strong winter monsoon pattern, are simulated somewhat weakly in CMIP5 compared to observation. However, the spatial distributions of regressed SLP, $\mathrm{T} 2 \mathrm{~m}, \mathrm{Z500}$, and U300 are well established with a pattern correlation of more than 0.83 between CMIP5 and observation data. In addition, simulated teleconnections among the climatic indices including the EAWMIs are similar to observation. Because the characteristics of the EAWMIs and atmospheric variables in the EA region during DJF are well simulated, the boreal winter climate changes projected by RCPs are considered reliable and are analyzed further in more detail.

The projections indicate strong warming which increases with latitude ranging from 1 to $5{ }^{\circ} \mathrm{C}$ and from 3 to $7{ }^{\circ} \mathrm{C}$ under RCP4.5 and RCP8.5, respectively. This is due to the weakened SH and northward shift of AL, leading to the decreased horizontal pressure gradient between $\mathrm{SH}$ and NP regions, and resulting in the weakening of climatological northerly winds over Northeast Asia (Jiang and Tian 2013; Wang et al. 2013). The warming over the high latitude inland region is stronger than over the low latitude ocean region, which indicates that the meridional thermal contrast over EA is weakened. This differential warming also induces the weakened meridional geopotential gradient over EA, and consequently U300 weakens and moves northward compared to Historical. Thus, this process exhibits the weakening of EAWM in RCPs, which is consistent with some previous results (Hu et al. 2000; Hori and Ueda 2006) but not with others (e.g., Jiang and Tian 2013; Wei and Bao 2012). Jiang and Tian (2013) projected that the EAWM changes little over time (2000-2099) as a whole relative to the reference period (1980-1999) using 31 CMIP3 and CMIP5 climate models with A1B and RCP4.5 scenarios. Wei and Bao (2012) showed that the winter wind speeds increased in China for the 21st century due to a strengthened EAWM under RCP4.5 and RCP8.5 induced by a single climate model (IAP_FGOALS) participating in CMIP5.It is worth noting that the projections of future EAWM change are somewhat model- and indexdependent (Jiang and Tian 2013).
The decreasing trend in the EAWMIs and increasing trend in EA-T2m are significant in RCP8.5 compared to RCP4.5. The matching between years of projected weak monsoon and warm EA-T2m also remains valid in the RCP projections. However, the projected relationship between the strong monsoon and cold EA-T2m is not well matched compared to Historical. The projected interannual variations of the EAWMIs are significant, as in Historical. On the whole, the predominant periods of the EAWMIs in RCP4.5 are similar to those in Historical, but those in RCP8.5 are longer than those in Historical. This implies that the occurrences of strong EAWM are expected to decrease in RCP8.5.

The correlations between the EAWMIs in both RCPs are robust like Historical. However, the relations between the EAWMIs and other climate indices in RCPs differ somewhat from those in Historical. The negative correlations between the NP index and the EAWMIs (except for $\mathrm{I}_{\mathrm{WH}}$ ) in RCP4.5 are significant, similar to Historical, whereas those in RCP8.5 are weak compared to Historical. The relationships between NAO and NP indices increase in RCP4.5 and decrease in RCP8.5. The correlations between the EAWMIs and the AO index increase, while the correlations between the EAWMIs and the NAO index decrease in both RCPs compared to Historical. These results represent the increased complexity of predictability concerning the EAWM interannual variations in future projections (Wei and Bao 2012).

The EAWM is characterized by strong surface northerlies along the coastal region, which curve around the east side of the SH. In the northern and southern parts (divided around $30^{\circ} \mathrm{N}$ ), the EAWM is characterized by northwesterlies and northeasterlies, respectively. Therefore, the EA$\mathrm{T} 2 \mathrm{~m}$ index in this study $\left(30^{\circ} \mathrm{N}-50^{\circ} \mathrm{N}, 110^{\circ} \mathrm{E}-140^{\circ} \mathrm{E}\right)$ actually reflects the $\mathrm{T} 2 \mathrm{~m}$ change in the northern part of the EAWM region. According to previous studies (e.g., Wang et al. 2010; Wei and Bao 2012; Wei et al. 2015), this actually delineates the first/northern mode of the T2m interannual variability in the EAWM region. Therefore, the EA$\mathrm{T} 2 \mathrm{~m}$ and the three EAWMIs used in this study are more favorable to describe the variation of EAWM in the northern part of the EA region (north of $30^{\circ} \mathrm{N}$ ).

The uncertainties in climate projection result from the climate change scenarios, models and analysis periods. Furthermore, the observation error restricts our understanding of climate change and our knowledge of natural climate variability is also limited (Jiang and Tian 2013). These limitations necessitate further research on climate change projection using various models and on the use of EAWMIs to reduce the degree of uncertainties.

Acknowledgments This work was funded by the Korea Meteorological Administration Research and Development Program under grant KMIPA 2015-2081 and carried out with the support of Rural 
Development Administration Cooperative Research Program for Agriculture Science and Technology Development under Grant Project No. PJ009953, Republic of Korea.

Open Access This article is distributed under the terms of the Creative Commons Attribution 4.0 International License (http://creativecommons.org/licenses/by/4.0/), which permits unrestricted use, distribution, and reproduction in any medium, provided you give appropriate credit to the original author(s) and the source, provide a link to the Creative Commons license, and indicate if changes were made.

\section{References}

Alexeev VA, Langen PL, Bates JR (2005) Polar amplification of surface warming on an aquaplanet in "ghost forcing" experiments without sea ice feedbacks. Clim Dyn 24:655-666. doi:10.1007/ s00382-005-0018-3

Bueh C (2003) Simulation of the future change of East Asian monsoon climate using the IPCC SRES A2 and B2 scenarios. Chin Sci Bull 48:1024-1030. doi:10.1007/BF03184220

Cai M (2005) Dynamical amplification of polar warming. Geophys Res Lett 32:L22710. doi:10.1029/2005GL024481

Chan JCL, Li CY (2004) The East Asia winter monsoon. In: Chang CP (ed) East Asian Monsoon. World Scientific, New Jersey, pp $54-106$

Chang CP, Wang Z, Hendon H (2006) The Asian winter monsoon. In: Wang B (ed) The Asian Monsoon. Springer, New York, pp $89-127$

Chen H, Sun J (2013) Projected change in East Asian summer monsoon precipitation under RCP scenario. Meteorol Atmos Phys 121:55-77

Chen W, Yang S, Huang RH (2005) Relationship between stationary planetary wave activity and the East Asian winter monsoon. J Geophys Res 110:D14110. doi:10.1029/2004JD005669

Comiso JC, Parkinson CL, Gersten R, Stock L (2008) Accelerated decline in the Arctic sea ice cover. Geophys Res Lett 35:L01703. doi:10.1029/2007GL031972

Gao H (2007) Comparison of East Asian winter monsoon indices. Adv Geosci 10:31-37

Gong DY, Wang SW, Zhu JH (2001) East Asian winter monsoon and arctic oscillation. Geophys Res Lett 28:2073-2076

Gong H, Wang L, Chen W, Wu R, Wei K, Cui X (2014) The climatology and interannual variability of the East Asian winter monsoon in CMIP5 models. J Clim 27:1659-1678. doi:10.1175/ JCLI-D-13-00039.1

Graversen R, Wang M (2009) Polar amplification in a coupled climate model with locked albedo. Clim Dyn 33:629-643. doi:10.1007/ s00382-009-0535-6

Hori ME, Ueda H (2006) Impact of global warming on the East Asian winter monsoon as revealed by nine coupled atmosphereocean GCMs. Geophys Res Lett 33:L03713. doi:10.1029/200 5GL024961

Hu ZZ, Bengtsson L, Arpe K (2000) Impact of global warming on the Asian winter monsoon in a coupled GCM. J Geophys Res 105:4607-4624. doi:10.1029/1999JD901031

Huang R, Chen W, Yan B, Zhang R (2004) Recent advances in studies of the interaction between the East Asian winter and summer monsoons and ENSO cycle. Adv Atmos Sci 21:407-424

Hurrell JW (1995) Decadal trends in the North Atlantic Oscillation: Regional temperatures and precipitation. Science 269:676-679

IPCC (2000) Special report on emissions scenarios: a special report of working group III of the intergovernmental panel on climate change. Cambridge University, Cambridge
Jhun JG, Lee EJ (2004) A new East Asian winter monsoon index and associated characteristics of the winter monsoon. J Clim 17:711-726

Ji LR, Sun SQ, Arpe K, Bengtsson L (1997) Model study on the interannual variability of Asian winter monsoon and its influence. Adv Atmos Sci 14:1-22. doi:10.1007/s00376-997-0039-4

Jiang DB, Tian ZP (2013) East Asian monsoon change for the 21st century: results of CMIP3 and CMIP5 models. Chin Sci Bull 58:1427-1435. doi:10.1007/s11434-012-5533-0

Jiang DB, Wang HJ, Lang XM (2005) Evaluation of East Asian climatology as simulated by seven coupled models. Adv Atmos Sci 22:479-495

Kharin VV, Zwiers FW, Zhang X, Hegerl GC (2007) Changes in temperature and precipitation extremes in the IPCC ensemble of global coupled model simulations. J Clim 20:1419-1444. doi:10.1175/JCLI4066.1

Kug JS, Choi DH, Jin FF, Kwon WT, Ren HL (2010) Role of synoptic eddy feedback on polar climate responses to the anthropogenic forcing. Geophys Res Lett 37:L14704. doi:10.1029/201 0GL043673

Kumar A, Perlwitz J, Eischeid J, Quan X, Xu T, Zhang T, Hoerling M, Jha B, Wang W (2010) Contribution of sea ice loss to Arctic amplification. Geophys Res Lett 37:L21701. doi:10.1029/20 10GL045022

Langen PL, Alexeev VA (2007) Polar amplification as a preferred response in an idealized aquaplanet GCM. Clim Dyn 29:305317. doi:10.1007/s00382-006-0221-x

Lau KM, Chang CP (1987) Planetary scale aspects of the winter monsoon and atmospheric teleconnections. In: Meteorology M (ed) Chang and Krishnamurti. Oxford University, New York, pp 161-202

Lau KM, Li MT (1984) The monsoon of East Asia and its global associations-A survey. Bull Am Meteorol Soc 65:114-125. doi:10.1175/1520-0477(1984)065<0114:TMOEAA >2.0.CO;2

Lee SS, Kim SH, Jhun JG, Ha KJ, Seo YW (2013) Robust warming over East Asia during the boreal winter monsoon and its possible causes. Environ Res Lett 8:034001. doi:10.1088/1748-9326/8/3/034001

Li Y, Yang S (2010) A dynamical index for the East Asian winter monsoon. J Clim 23:4255-4262. doi:10.1175/2010JCLI3375.1

Li Y, Lu R, Dong B (2007) The ENSO-Asian monsoon interaction in a coupled ocean-atmosphere GCM. J Clim 20:5164-5177

Liu JP, Curry JA, Wang HJ, Song MR, Horton RM (2012) Impact of declining Arctic sea ice on winter snowfall. Proc Natl Acad Sci USA 109:6781-6783. doi:10.1073/pnas.1114910109

Lu E, Chan JCL (1999) A unified monsoon index for South China. J Clim 12:2375-2385. doi:10.1175/1520-0442(1999)012<2375:AUMIFS $>2.0 . \mathrm{CO} ; 2$

Rayner NA, Parker DE, Horton EB, Folland CK, Alexander LV, Rowell DP, Kent EC, Kaplan A (2003) Global analyses of sea surface temperature, sea ice, and night marine air temperature since the late nineteenth century. J Geophys Res 108:4407. doi:10.1029/2 002JD002670,D14

Serreze MC, Barrett AP, Slater AG, Steele M, Zhang JL, Trenberth KE (2007) The large-scale energy budget of the Arctic. J Geophys Res 112:D11122. doi:10.1029/2006JD008230

Soden B, Held I, Colman R, Shell K, Kiehl J, Shields C (2008) Quantifying climate feedbacks using radiative kernels. J Clim 21:3504-3520. doi:10.1175/2007JCLI2110.1

Sperber KR, Annamalai H, Kang IS, Kitoh A, Moise A, Turner A, Wang B, Zhou T (2012) The Asian summer monsoon: an intercomparison of CMIP5 vs. CMIP3 simulations of the late 20th century. Clim Dyn 41:2711-2744

Taylor KE, Stouffer RJ, Meehl GA (2012) An overview of CMIP5 and the experiment design. Bull Am Meteorol Soc 93:485-498 
Thompson DWJ, Wallace JM (1998) The Arctic Oscillation signature in the wintertime geopotential height and temperature fields. Geophys Res Lett 25:1297-1300

Trenberth KE, Hurrell JW (1994) Decadal atmosphere-ocean variations in the Pacific. Clim Dyn 9:303-319

Uppala SM, KÅllberg PW, Simmons AJ et al (2005) The ERA-40 re-analysis. Q J R Meteorol Soc 131:2961-3012. doi:10.1256/ qj.04.176

Wallace JM (2000) North Atlantic oscillation/annular mode: two paradigms-one phenomenon. Q J R Meteorol Soc 126:791-805. doi:10.1256/smsqj.56401

Wang L, Chen W (2010) How well do existing indices measure the strength of the East Asian winter monsoon? Adv Atmos Sci 27:855-870. doi:10.1007/s00376-009-9094-3

Wang L, Chen W (2014) An intensity index for the East Asian Winter monsoon. J Clim 27:2361-2374. doi:10.1175/ JCLI-D-13-00086.1

Wang H, He S (2012) Weakening relationship between East Asian winter monsoon and ENSO after mid-1970s. Chin Sci Bull 57:3535-3540. doi:10.1007/s11434-012-5285-x

Wang B, Wu R, Lau KM (2001) Interannual variability of the Asian summer monsoon: contrasts between the Indian and the western North Pacific-East Asian monsoons. J Clim 14:4073-4090. doi:10.1175/1520-0442(2001)014<4073:IVOTAS>2.0.CO;2

Wang L, Chen W, Huang R (2008) Interdecadal modulation of PDO on the impact of ENSO on the East Asian winter monsoon. Geophys Res Lett 35:L20702

Wang L, Chen W, Zhou W, Huang R (2009a) Interannual variations of East Asian trough axis at $500 \mathrm{hPa}$ and its association with the East Asian winter monsoon pathway. J Clim 22:600-614. doi:10. 1175/2008JCLI2295.1

Wang L, Huang R, Gu L, Chen W, Kang L (2009b) Interdecadal variations of the East Asian winter monsoon and their association with quasi-stationary planetary wave activity. J Clim 22:48604872. doi:10.1175/2009JCLI2973.1

Wang B, Wu Z, Chang CP, Liu J, Li J, Zhou T (2010) Another look at interannual-to-interdecadal variations of the East Asian winter monsoon: the northern and southern temperature modes. J Clim 23:1495-1512. doi:10.1175/2009JCLI3243.1
Wang H, He S, Liu J (2013) Present and future relationship between the East Asian winter monsoon and ENSO: results of CMIP5. J Geophys Res Oceans 118:5222-5237. doi:10.1002/jgrc.20332

Watanabe M, Nitta T (1999) Decadal changes in the atmospheric circulation and associated surface climate variations in the Northern Hemisphere winter. J Clim 12:494-510. doi:10.1175/1520-0442(1999)012<0494:DCITAC >2.0.CO;2

Wei K, Bao Q (2012) Projections of the East Asian winter monsoon under the IPCC AR5 scenarios using a coupled model: IAP_FGOALS. Adv Atmos Sci 29:1200-1213. doi:10.1007/s00376-012-1226-5

Wei K, Xu T, Du Z, Gong H, Xie B (2014) How well do the current state-of-the-art CMIP5 models characterize the climatology of the East Asian winter monsoon? Clim Dyn 43:1241-1255. doi:10.1007/s00382-013-1929-Z

Wei K, Takahashi M, Chen W (2015) Long-term changes in the relationship between stratospheric circulation and East Asian winter monsoon. Atmos Sci Lett 16:359-365. doi:10.1002/as12.568

Wu B, Wang J (2002) Winter arctic oscillation, Siberian high and East Asian winter monsoon. Geophys Res Lett 29:1897. doi:10.1029 /2002GL015373

Yanai M, Wu GX (2006) Effects of the Tibetan Plateau. In: Wang B (ed) The Asian Monsoon. Springer, New York, pp 513-549

Yang S, Lau KM, Kim KM (2002) Variations of the East Asian jet stream and Asian-Pacific-American winter climate anomalies. J Clim 15:306-325. doi:10.1175/1520-0442(2002)015<0306:VOT EAJ $>2.0 . \mathrm{CO} ; 2$

Zhang R, Sumi A, Kimoto M (1996) Impact of El Niño on the East Asian monsoon: a diagnostic study of the ' $86 / 87$ and ' $91 / 92$ events. J Meteorol Soc Japan 74:49-62

Zhisheng A, Kutzbach JE, Prell WL, Porter SC (2001) Evolution of Asian monsoons and phased uplift of the HimalayaTibetan plateau since Late Miocene times. Nature 411:62-66. doi: $10.1038 / 35075035$

Zhu Y (2008) An index of East Asian winter monsoon applied to the description of China's mainland winter temperature changes. J Meteor Res 22:522-529 